\title{
Article \\ Biochemical Characterization of 13-Lipoxygenases of Arabidopsis thaliana
}

\author{
Daniel Maynard ${ }^{1}$, Kamel Chibani ${ }^{1}{ }^{\circledR}$, Sonja Schmidtpott ${ }^{1}$, Thorsten Seidel ${ }^{1}{ }^{\circledR}$, Jens Spross ${ }^{2}$, \\ Andrea Viehhauser ${ }^{1}$ (D) and Karl-Josef Dietz ${ }^{1, *(D)}$ \\ 1 Department of Biochemistry and Physiology of Plants, Faculty of Biology, University of Bielefeld, \\ 33615 Bielefeld, Germany; daniel.maynard@uni-bielefeld.de (D.M.); kamel.chibani@uni-bielefeld.de (K.C.); \\ sonjaschmidtpott10@gmail.com (S.S.); thorsten.seidel@uni-bielefeld.de (T.S.); \\ andrea.viehhauser@uni-bielefeld.de (A.V.) \\ 2 Faculty of Chemistry/Industrial Organic Chemistry and Biotechnology, University of Bielefeld, \\ 33615 Bielefeld, Germany; j.spross@uni-bielefeld.de \\ * Correspondence: karl-josef.dietz@uni-bielefeld.de; Tel.: +49-521-106-5589
}

Citation: Maynard, D.; Chibani, K.; Schmidtpott, S.; Seidel, T.; Spross, J.; Viehhauser, A.; Dietz, K.-J. Biochemical Characterization of 13-lipoxygenases of Arabidopsis thaliana. Int. J. Mol. Sci. 2021, 22, 10237. https://doi.org/10.3390/ ijms221910237

Academic Editor: Cristobal Miranda

Received: 2 July 2021

Accepted: 19 September 2021

Published: 23 September 2021

Publisher's Note: MDPI stays neutral with regard to jurisdictional claims in published maps and institutional affiliations.

Copyright: (c) 2021 by the authors. Licensee MDPI, Basel, Switzerland. This article is an open access article distributed under the terms and conditions of the Creative Commons Attribution (CC BY) license (https:/ / creativecommons.org/licenses/by/ $4.0 /)$.

\begin{abstract}
LOX) catalyze the dioxygenation of various polyunsaturated fatty acids (PUFAs), of which $\alpha$-linolenic acid (LeA) is converted to 13-S-hydroperoxyoctadeca-9, 11, 15-trienoic acid (13-HPOT), the precursor for the prostaglandin-like plant hormones cis-(+)-12oxophytodienoic acid (12-OPDA) and methyl jasmonate (MJ). This study aimed for characterizing the four annotated A. thaliana 13-LOX enzymes (LOX2, LOX3, LOX4, and LOX6) focusing on synthesis of 12-OPDA and 4Z,7Z,10Z)-12-[[-(1S,5S)-4-oxo-5-(2Z)-pent-2-en-1yl] cyclopent-2-en-1yl] dodeca4,7,10-trienoic acid (OCPD). In addition, we performed interaction studies of 13-LOXs with ions and molecules to advance our understanding of 13-LOX. Cell imaging indicated plastid targeting of fluorescent proteins fused to 13-LOXs-N-terminal extensions, supporting the prediction of 13-LOX localization to plastids. The apparent maximal velocity $\left(\mathrm{V}_{\text {max app }}\right)$ values for LOX-catalyzed LeA oxidation were highest for LOX4 $\left(128 \mathrm{nmol} \cdot \mathrm{s}^{-1} \cdot \mathrm{mg}_{\text {protein }}{ }^{-1}\right)$, with a $\mathrm{K}_{\mathrm{m}}$ value of $5.8 \mu \mathrm{M}$. A. thaliana 13-LOXs, in cascade with 12-OPDA pathway enzymes, synthesized 12-OPDA and OCPD from LeA and docosahexaenoic acid, previously shown only for LOX6. The activities of the four isoforms were differently affected by physiologically relevant chemicals, such as $\mathrm{Mg}^{2+}, \mathrm{Ca}^{2+}, \mathrm{Cu}^{2+}$ and $\mathrm{Cd}^{2+}$, and by 12-OPDA and MJ. As demonstrated for LOX4, 12-OPDA inhibited enzymatic LeA hydroperoxidation, with half-maximal enzyme inhibition at $48 \mu \mathrm{M}$. Biochemical interactions, such as the sensitivity of LOX toward thiol-reactive agents belonging to cyclopentenone prostaglandins, are suggested to occur in human LOX homologs. Furthermore, we conclude that 13-LOXs are isoforms with rather specific functional and regulatory enzymatic features.
\end{abstract}

Keywords: Arabidopsis thaliana; lipoxygenases; polyunsaturated fatty acids; lipoxygenase inhibitor; oxylipin

\section{Introduction}

Lipoxygenases (LOX, 1.13.11.X) are non-heme iron- or manganese-containing dioxygenases that occur in most eukaryotes and in some prokaryotes, and that play important roles in cell signaling [1]. LOX catalyze the oxidation of polyunsaturated fatty acids (PUFAs) into 1,3-pentadiene-conjugated PUFA hydroperoxides, which can be enzymatically processed by typical and atypical cytochrome P450 monooxygenases (CYP 74s) [2]. In humans, LOX-coupled cascades yield docosahexaenoic acid (DHA)- or arachidonic acid (ARA)-derived neuroprostanes, leukotrienes and prostaglandins of cyclopentanone- and cyclopentenone-types that are involved in development, signaling and defense [3,4]. Similar physiological processes are described in plants and fungi and involve oxidized PUFAs (oxylipins), such as 12-oxo-phytodienoic acid (12-OPDA), methyl jasmonate (MJ), traumatic acid (TA) or green leaf volatiles [5-7]. It is assumed that cyanobacteria and algae were 
the first living systems to utilize oxygen and PUFAs as LOX substrates and that oxylipin diversification was shaped by the evolution of catalase-related enzymes and oxylipin receptors $[1,8]$. The mentioned species usually express both 9-lipoxygenases (9-LOX) and 13-lipoxygenases (13-LOX), consisting of the catalytic LOX domain and a polycystin-1, lipoxygenase, alpha-toxin and triacylglycerol lipase (PLAT) domain. The role of the PLAT domain in function and evolution remains obscure. Recent reports demonstrated that prokaryotic LOX lacking the PLAT domain are fully active [1], whereas single PLAT proteins exist in eukaryotic organisms such as plants and display similar stress-associated functions as described for LOXs [9]. In mammals and humans (h), LOX12 and LOX15 a/b are 13-LOX-like enzymes in terms of linolenic acid (LeA) hydroperoxidation [10].

In the plant model of Arabidopsis thaliana (A. thaliana), LeA and linoleic acid (LA) are the major endogenous PUFAs, with percent ratios of LeA/LA near 3.3 in the leaves and 0.7 in roots [11]. Moreover, four 13-LOX isoforms, namely, LOX2, 6, 4 and 3 (ordered according to their relative abundance in the whole plant, see PAXdB https://pax-db.org/, accessed on 28 May 2021) are annotated as being highly selective toward the formation of 13-S-hydroperoxyoctadeca-9, 11, 15-trienoic acid (13-HPOT) from LeA. Among these, Bannenberg et al. [12] revealed a high instability of LOX2 and LOX6, whereas LOX3 and LOX4 were the most active 13-LOXs (for further details, see [12]). The 9-LOX1 and 5 are, however, reported to be active on both LeA and LA with similar activities, as observed for LOX3 and LOX4 [2,12]. Lipases specific for the cleavage of both PUFAs from respective glycolipids and phospholipids (for whole-plant abundancies, see [11]) hardly exist [13]. Therefore, information on how plant-derived 9-LOX and 13-LOX achieve or regulate their specificities in LA or LeA oxidation is incomplete and could be approached in studies similar to those on the hLOX-dependent orchestration of the PUFA metabolism [14].

$\alpha$-Dioxygenase 1 (DOX1), 9-LOX and 13-LOX channel the PUFA oxidation products into competing metabolic pathways. In addition, at least seven oxylipin-generating enzymes act on 13-HPOT. Among these, the Cyp74s, allene oxide synthase (AOS) and hydroperoxide lyase (HPL) are best described. AOS, in conjugation with the functional redundant allene oxide cyclases 1-4 (AOC), are responsible for the biosynthesis of 12-OPDA, while HPL delivers traumatic acid (TA) and green-leaf volatiles [15]. Depending on the physiological state, 12-OPDA is converted to JA in four reactions. Briefly, 12-oxophytodienoic acid reductase 3 (OPR3) mediates the cyclopentenone $(\mathrm{CP})$ reduction. The carboxyl sidechain is subsequently shortened three times via ATP-dependent CoA-ligases and FA oxidation-related enzymes [15]. Stelmach et al. [16] reported that $A$. thaliana, followed by Zea mays and barley, are the angiosperms most rich in 12-OPDA.

While the compartmentation of oxylipin metabolism is understood, the subcellular distribution of oxylipins and intermediates is essentially unknown. If we assume that 12OPDA is rapidly processed upon export to the extrachloroplast space, the total 12-OPDA contents would reflect the chloroplast pool, allowing estimating chloroplast 12-OPDA concentrations that are close to or higher than $30 \mu \mathrm{M}$ in these high 12-OPDA species after wounding. Of the 13-LOX enzymes, LOX6 is essential for adjusting the basal 12-OPDA level in roots and leaves [17], while LOX2 serves as the enzyme involved in the bulk synthesis of 12-OPDA in leaves [18]. Ziegler et al. [19] showed the insensitivity of AOS and AOC toward 12-OPDA at $0.5 \mathrm{mM}$ and $\mathrm{Ca}^{2+}$ or $\mathrm{Mg}^{2+}$ at $1.0 \mathrm{mM}$, while the effect of 12-OPDA and divalent cations on At-13-LOX activity has not yet been addressed to the best of our knowledge.

It appeared timely to comparatively address and extend knowledge on biochemical properties of 13-LOX first addressed by Bannenberg et al. [12].

\section{Results}

2.1. In Silico and Subcellular Targeting of Arabidopsis 13-Lipoxygenases

Based on annotations in publicly available databases and using bioinformatics tools (see Section 4.1), the amino acids sequences of the four 13-LOX isoforms were dissected into putative chloroplast transit sequences, as well as PLAT and catalytic LOX domains 
(Figure 1A). The 13-LOX sequences differed in length, amino acid composition and physicochemical properties. The calculated isoelectric points $(\mathrm{pI})$ of the LOX domains ranged between 5.2 and 6.2. A major difference was seen for the PLAT domain; while LOX6, LOX4 and LOX3 had a basic pI value (9.1-9.5), the respective domain of LOX2 was strongly acidic (4.8). Distinct characteristics of 13-LOXs were seen when comparing their amino acid sequences, revealing that LOX3 and LOX4 are similar, with $85.0 \%$ identity, but only $53 \%$ identical to LOX6 and $45 \%$ to LOX2, whereas LOX2 is $49 \%$ identical to LOX6 [20]. Among the conserved features are metal cofactor-coordinating amino acid residues and the determinants for regio- and stereospecificity (for conventions, see [21]). In addition, the absence of the amino acids typical for manganese LOX, such as Phe 332 or Phe 526, supports 13-LOXs annotation as Fe-LOXs [22]. Interestingly, invariant Trp and one or two Cys residues are located in the PLAT domain of 13-LOX (see domain map Figure 1A). In conjunction with the participation of the PLAT domain in LOX stabilization [23-25] and binding to LOX inhibitors, this in silico finding served as a starting point for further studies, as addressed below. Taking into account all active site residues identified or suggested before [20], it is noteworthy that a Pro residue in LOX3 and LOX4 and a Thr residue in LOX2 and LOX6 are in proximity to the 13-S determining Phe (Figure 1B). The 3D models presenting 13-LOXs and their active sites are shown in Figure 1B,C.

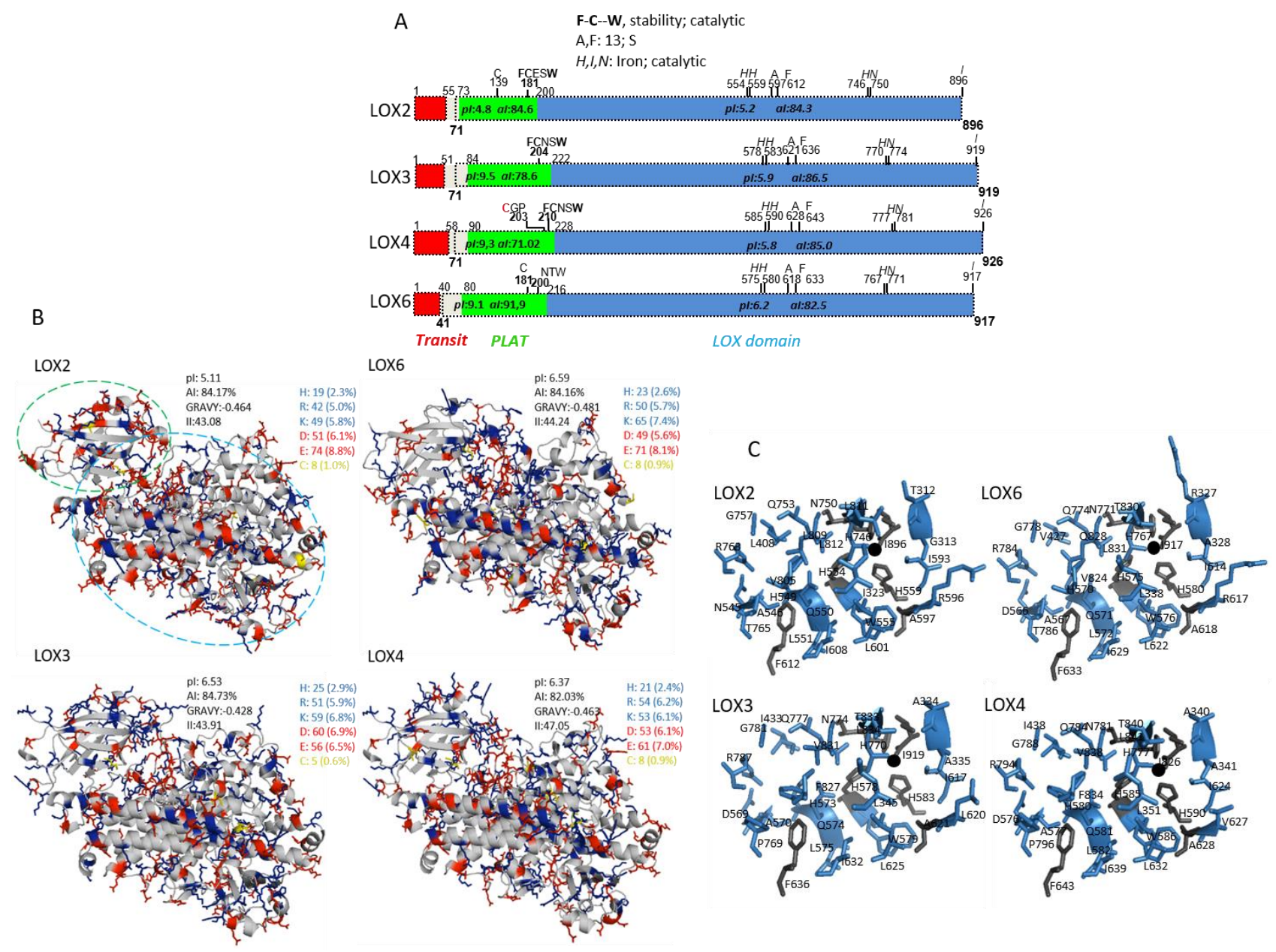

Figure 1. In silico analysis of At-13-LOXs. (A) Domain maps of 13-LOXs. (B) 3D models of 13-LOX enzymes, highlighting cysteinyl and charged amino acid residues. Tertiary structures of 13-LOX models, based on the crystal structure of SLOX (4wfo), are depicted in grey. Basic $(K, R, H)$ and acidic (D, E) amino acid side-chains (AA) that are positively and negatively charged under physiological $\mathrm{pH}$ values are depicted as sticks in blue and red. Of the aliphatic index (AI) determining AA, only Cys (yellow) are shown. The amount and percentage of the $\mathrm{pI}$ value determining AA in each 13-LOX, together with Cys residues, are also listed. The PLAT and LOX domains exemplified for LOX2 are circled. (C) Active sites (backbone not shown) of 13-LOX are depicted in blue in reference to (A), with 13-S determining and catalytic residues highlighted in black. 
Arabidopsis 13-LOX enzymes are most probably plastid-localized, due to their Nterminal extension $[2,12,15]$. To explore their subcellular targeting, we fused yellow fluorescent protein (YFP) downstream of the putative transit peptide sequences of LOXs, and transiently expressed these constructs in protoplasts isolated from A. thaliana leaves in a similar manner, as described for the analysis of rice LOX-1 (Q9FSE5, [26]). As seen in Figure 2, the distribution of the 13-LOX transit peptide:YFP protein fusions matched the pattern of chlorophyll autofluorescence. Merging these images proved co-localization, and indicated that the predicted 13-LOX plastid transit peptides are sufficient to target the reporters to the plastids.

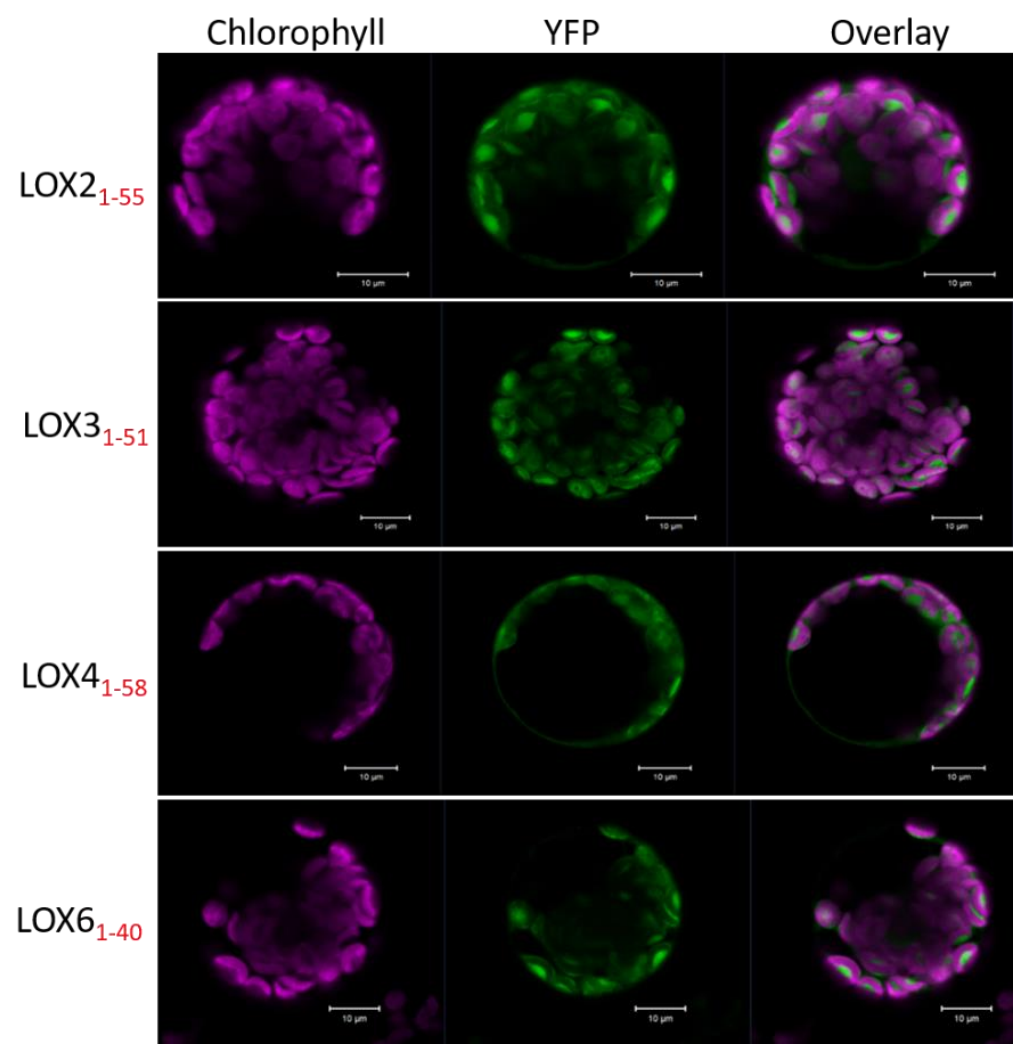

Figure 2. Subcellular localization of fusions of 13-LOXs N-terminal sequences with YFP. Fluorescence microscopic analyses of $A$. thaliana protoplasts transfected with YFP-constructs (LOX2 $1-55-Y F P$, LOX $_{1-51}$-YFP, LOX4 $1-58$-YFP, LOX6 ${ }_{1-40}$-YFP) revealed that the indicated sequences target the reporter to the chloroplast, as shown by the overlay (merge) of the YFP fluorescence signal (green) with chloroplast autofluorescence (magenta). The same pattern of co-localization was observed in several protoplasts. Size bars: $10 \mu \mathrm{m}$.

\subsection{Purification and Enzymatic Characteristics of Arabidopsis 13-Lipoxygenases}

To gain further information on biochemical properties, the sequences encoding the mature At-13-LOXs (LOX271-896, LOX371-919, LOX471-926, LOX641-917) were placed as Histag fusion constructs under the control of the IPTG-inducible promoter in E. coli expression vectors. This followed the strategies described in previous reports $[21,27,28]$. Total proteins were extracted from induced expression strains by mild sonication, and the soluble fusion proteins were obtained in the supernatant containing active LOXs. No activities were observed using control homogenates prepared from E. coli cells devoid of LOX plasmids, or when 13-LOX-containing solutions had been boiled $\left(30 \mathrm{~s}, 85^{\circ} \mathrm{C}\right)$. As shown for LOX6, (see Supplementary Figure S1) this demonstrated that the herein-utilized 13-LOX protein sources were active and specific for PUFA oxidation, containing no impurities that would have caused the unspecific oxidation of PUFA. The theoretical and, thus, expected molecular masses of the recombinant His-tagged 13-LOX were 95,061, 96,791, 97,830 and 
100,912 kDa. As judged by SDS-PAGE analysis, dominant bands appeared at the expected mass size (see Figure S2), the proteins were estimated as being of $\sim 90 \%$ (LOX4), $\sim 80 \%$ (LOX2 and LOX3) and 50\% (LOX6) purity. LOX3, LOX4 and LOX6, unlike LOX2, were enriched by $\sim 5$-fold when cleared lysates were purified via metal affinity chromatography. This is demonstrated via SDS-PAGE (Figure S2) and activity analysis (activity analysis is shown for LOX6 in Figure S1). Further attempts to purify 13-LOX were not performed due to our observation of unexpected elution positions during gel-filtration (see Figure S2D) and the instability of 13-LOX [12]. We thus decided to utilize LOX3, LOX4 and LOX6 eluates and LOX2-cleared lysate for subsequent 13-LOX analysis, if not mentioned otherwise.

To analyze the role of 13-LOXs as putative Fe-LOXs (see Section 2.1), we analyzed their iron contents using the ferrozine assay (see Section 4.9), revealing Fe/LOX ratios ( $\mathrm{mol} / \mathrm{mol}$, means $\pm \mathrm{SD}$ of $\mathrm{n} \geq 4$ ) of $0.48 \pm 0.1$ (LOX2), $0.36 \pm 0.1$ (LOX3), $0.40 \pm 0.1$ (LOX4) and $0.27 \pm 0.06$ (LOX6). The detected iron loads above $20 \%$ clearly assign 13-LOXs as Fe-LOXs [29,30], as suggested in Section 2.1.

As chloroplast $\mathrm{pH}$-values range between 7.0 in the dark and $>8.0$ in the light, we recorded the activities of 13-LOX with their optimal substrate LeA between $\mathrm{pH} 6.6$ and 8.6 , to detect the pH-optima of 13-LOX. All members showed high activity around neutral $\mathrm{pH}$ and low activity at $\mathrm{pH} 8.6$ (Figure S2C). LOX2 was most sensitive and LOX4 was least sensitive toward $\mathrm{pH}$ changes. At $\mathrm{pH} 6.6, \mathrm{LOX} 3$ and LOX6 activity were lowered by $\sim 30 \%$, in contrast to LOX2 and LOX4, when compared to their optimal $\mathrm{pH}$ values at $\mathrm{pH} 6.6$ $\left(3.9 \pm 0.4 \mathrm{nmol} \cdot \mathrm{s}^{-1} \cdot \mathrm{mg}^{-1}\right)$ and $\mathrm{pH} 7.2\left(62.3 \pm 0.4 \mathrm{nmol} \cdot \mathrm{s}^{-1} \cdot \mathrm{mg}^{-1}\right)$. The apparent affinities of 13-LOX enzymes toward LeA were highest for LOX6 $\left(\mathrm{K}_{\text {m app }}=1.2 \pm 0.4 \mu \mathrm{M}\right)$ and lowest for LOX2 $\left(\mathrm{K}_{m \text { app }}=26.3 \pm 2 \mu \mathrm{M}\right)$. The respective velocities of product formation were highest for LOX3 and LOX4 and lowest for LOX2 and LOX6, the latter two had apparent $\mathrm{V}_{\max }$-values 45 -fold lower than that of LOX4 $\left(128 \pm 18 \mathrm{nmol} \cdot \mathrm{s}^{-1} \cdot \mathrm{mg}^{-1}\right)$, which is partly due to the different degrees of purity. The purities and iron loads below 100\% were not considered in the activity calculation or related properties studied herein.

The enzymatic parameters of LOX isoforms, with LA as substrate, could only be determined for LOX2 (for more details, see Figure 3 and Figure S3). Relative to LeA, LOX2 was unusually effective in LA- (79\%) and ARA-oxygenation (50\%) (Table 1).
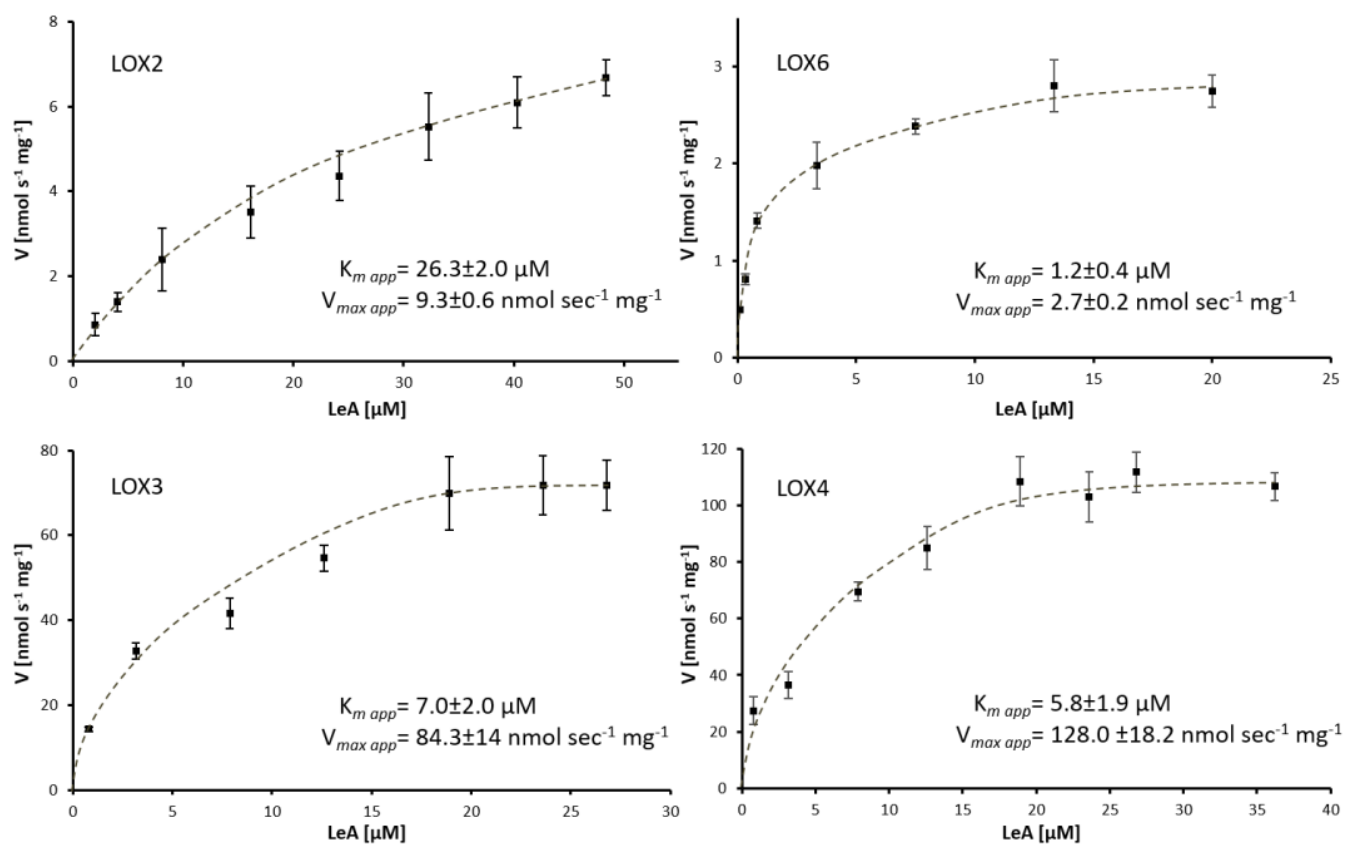

Figure 3. Activity of 13-LOX with their favored substrate, LeA. Graphs are means \pm SD of $n \geq 3$, derived from a nonlinear regression fit using the Michaelis Menten equation. The apparent (app) value is added to the parameters in order to indicate that 13-LOX enzymes differed in purity and iron load. For more details, see text and Section 4. 
Table 1. Substrate specificities of LOX2, LOX3, LOX4 and LOX6.

\begin{tabular}{ccccc}
\hline \multirow{2}{*}{ PUFA } & \multicolumn{4}{c}{ Relative Activity (\%) } \\
\cline { 2 - 5 } & LOX2 & LOX3 & LOX4 & LOX6 \\
\hline LeA & 100 & 100 & 100 & 100 \\
\hline LA & $79 \pm 7$ & $12 \pm 1$ & $11 \pm 1$ & $17 \pm 1$ \\
\hline ARA & $50 \pm 4$ & $5 \pm 1$ & $4 \pm 1$ & $8 \pm 3$ \\
\hline DHA & $56 \pm 3$ & $7 \pm 1$ & $8 \pm 1$ & $31 \pm 3$ \\
\hline
\end{tabular}

Activities were determined spectrophotometrically at a wavelength of $234 \mathrm{~nm}$, employing $4 \mu \mathrm{g}$ 13-LOX and $31 \mu \mathrm{M}$ PUFA in $50 \mathrm{mM}$ Tris-HCl, pH 7.2, in a total volume of $128 \mu \mathrm{L}$. Here, $100 \%$ refers to the activities $\left(\mathrm{nmol} \cdot \mathrm{s}^{-1} \cdot \mathrm{mg}^{-1}\right)$ obtained with LeA, LOX2: $4.4 \pm$ 0.3, LOX3: $71 \pm 2$, LOX4: $118 \pm 2$, LOX6: $2.3 \pm 0.2$. All values are means \pm SD of $\mathrm{n} \geq 3$.

Regarding LOX2 oxygenates LA at $\omega-6$ (13-HPOD) [12], as revealed from RP-HPLC analysis (Figure S4A), 15-(S)-hydroperoxy-5(Z),8(Z),11(Z),13(E)-eicosatetraenoic acid (15HPETE) was the oxylipin predominantly formed by LOX2 from ARA and displayed retention times (Rt) of $12.5 \mathrm{~min}$ (Rt 15-HPETE $12.5 \mathrm{~min}$ ). As shown spectrophotometrically, all three LOX2-derived peroxides were metabolized by AOS (Figure S4B), which is supportive to the turnover of $\omega-6$ oxygenated PUFAs by AOS of rice and Zea mays [31,32].

We intentionally tested whether the 22:6 ( $\omega-3)$ PUFA DHA is a substrate of 13-LOX. As shown in Table 1, 13-LOX enzymes dioxygenated DHA, with rates of $\sim 7$ to $56 \%$ relative to LeA, of which LOX2 was the most active enzyme. In line with the previous data on SLOX and LOX6 [33], a dominant oxylipin derivative of DHA, after incubation of DHA with LOX2, fractioned at Rt $\sim 13 \mathrm{~min}$. The MS analysis of this fraction revealed the presence of $\mathrm{HPDH}$, as indicated by the major signal appearing at $m / z$ of 383.2 due to the association of HPDH (MW $=360.5 \mathrm{~g} \cdot \mathrm{mol}^{-1}$ ) with sodium $[\mathrm{M}+\mathrm{Na}]^{+}$. The molecular ion was subjugated to an $\mathrm{MS}^{2}$ experiment and the formation of the fragment ion $\mathrm{m} / \mathrm{z} 297$ confirmed the position of hydroperoxidation at $\omega-6$, due to the loss of an 86 Da fragment $\left(\mathrm{C}_{5} \mathrm{H}_{10} \mathrm{O}\right)$, in accordance with the findings of [33]. This hypothesis was further endorsed by the confirmation of the sum formulas of the molecular ion and the $m / z 297.2$ fragment ion (Figure S5 and Table S2). The specificity of LOX3 and LOX4 was rather poor for producing 17-HPDH (see Figure S5). We observed that 13-LOXs were highly sensitive toward PUFAs or their oxidation products, whereas LOX2 was most robust. As analyzed for their favored substrates, more than $50 \%$ inhibition occurred when the enzymes $(0.22 \mu \mathrm{g} / \mu \mathrm{L})$ were pre-incubated with $29 \mu \mathrm{M}$ LA (LOX6) or $118 \mu \mathrm{M}$ LA (LOX3 and LOX4). The effect of LA and LeA on 13-LOX inhibition is depicted in Figure S6, revealing similar trends when pre-incubated with LeA.

\subsection{Arabidopsis 13-LOX Isoforms Mediate the Synthesis of 12-OPDA and OCPD}

13-HPOT is the substrate for the subsequent synthesis of 12-OPDA. As shown previously for LOX6 [33], 12-OPDA was produced by all At-LOX lysates, coupled to AOS and $A O C$, as revealed by the comparison of retention times with the standard (Figure 4).

The result underscores the involvement of 13-LOXs in 12-OPDA synthesis and the potential mechanism of feedback modulation by 12-OPDA, as investigated below. Due to the aforementioned criteria, LOX2 was, thus, utilized for OCPD synthesis. As revealed by the comparison of retention times with the OCPD standard, LOX2 like SLOX and LOX6, coupled in a one-pot synthesis with AOS and AOC [33], enabled the formation of the promising bioactive compound OCPD from DHA.

\subsection{Effect of Metal Ions and LOX-Associated Phytohormones on Arabidopsis 13-LOX Activities}

$\mathrm{Ca}^{2+}$ and $\mathrm{Mg}^{2+}$ play important roles in enzyme regulation. Stromal $\mathrm{Mg}^{2+}$ increases in the light phase, when the $\mathrm{pH}$ is $>8.0$ [34]. In addition, the activities of mammalian and plant lipoxygenases are affected by divalent cations $[23,35,36]$. Therefore, we investigated whether the same result occurs for 13-LOXs and included activity studies with $\mathrm{Cu}^{2+}$ and $\mathrm{Cd}^{2+}$. At a tested concentration of $1 \mathrm{mM}, 13-\mathrm{LOX}$ enzymes were differentially stimulated by $\mathrm{Ca}^{2+}$ and $\mathrm{Mg}^{2+}$. In comparison to control (mean values $\mathrm{n} \geq 3$ ), LOX2 activity increased more 
in the presence of $1 \mathrm{mM} \mathrm{Ca}^{2+}(590 \%)$ than $1 \mathrm{mM} \mathrm{Mg}^{2+}(70 \%)$. LOX4 and LOX3 were slightly activated $(6 \%$ and $35 \%)$ by $\mathrm{Mg}^{2+}$, whereas $\mathrm{Ca}^{2+}$ stimulated LOX3 activity. $\mathrm{Ca}^{2+}$ and $\mathrm{Mg}^{2+}$ enhanced LOX6-catalyzed oxygen consumption by $21 \%$ and $42 \%$, respectively (Table 2 ).

A

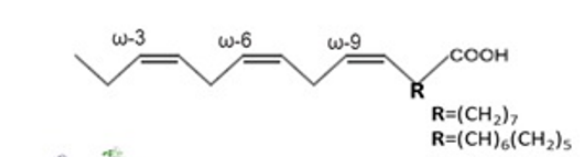

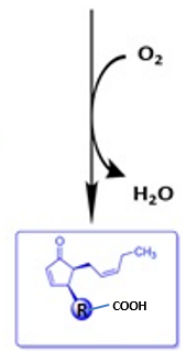

C

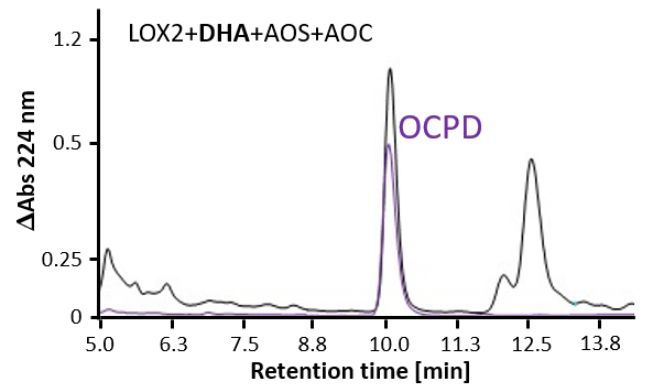

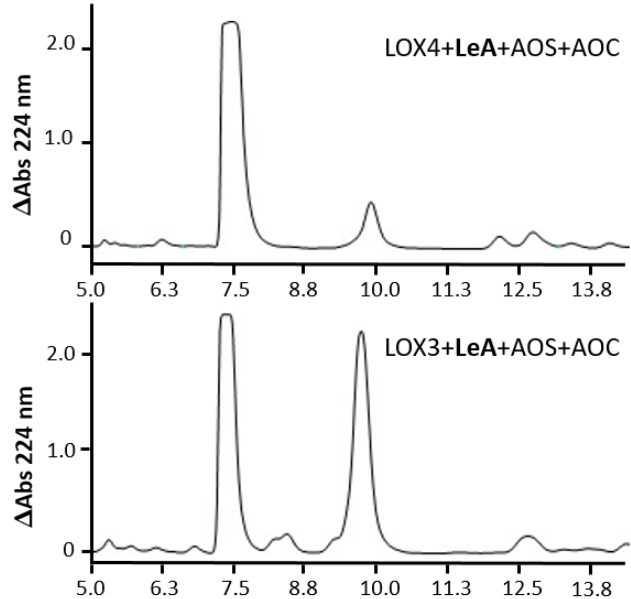
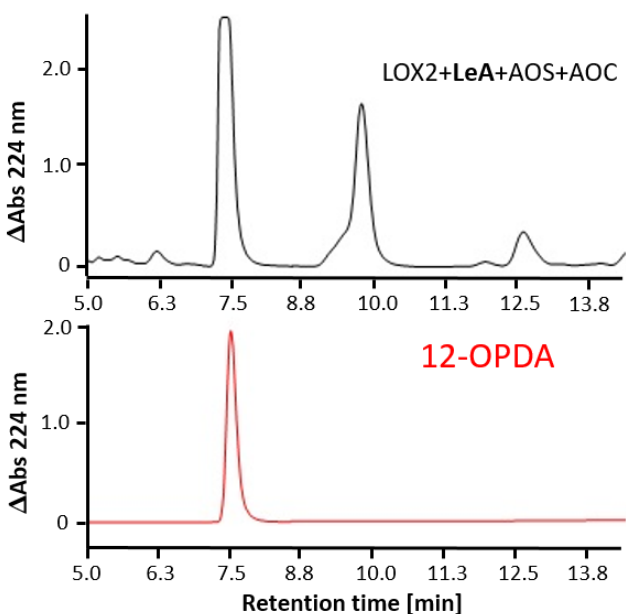

Figure 4. The 13-LOX mediated synthesis of 12-OPDA and OCPD. (A) Flow scheme for anticipated C18 and C22 CP synthesis from w-3 PUFAs LeA and DHA, with 3-D models of LOX2 (based on SLOX, 4wfo), AOS (3dsk) and AOC (1z8k). (B) RP-HPLC analysis of 12-OPDA and (C) OCPD one-pot synthesis extracts, the peak of high intensity appearing at 7.4-7.5 min and 10.1 min corresponded to LeA- and DHA-derived 12-OPDA and OCPD, as revealed by a comparison with the retention times of standards.

Table 2. Effect of divalent metals on 13-LOX activity.

\begin{tabular}{ccccc}
\hline \multirow{2}{*}{ Metal Salts } & \multicolumn{4}{c}{ Relative Activity (\%) } \\
\cline { 2 - 5 } & LOX2 & LOX3 & LOX4 & LOX6 \\
\hline $\mathrm{CaCl}_{2}(1 \mathrm{mM})$ & $690 \pm 6 \%^{*}$ & $117 \pm 10 \%{ }^{*}$ & $100 \pm 4 \%$ & $121 \pm 15 \%{ }^{*}$ \\
\hline $\mathrm{MgCl}_{2}(1 \mathrm{mM})$ & $170 \pm 18 \% *$ & $135 \pm 4 \%^{*}$ & $106 \pm 3 \%{ }^{*}$ & $142 \pm 15 \%{ }^{*}$ \\
\hline $\mathrm{CdSO}_{4}(1 \mathrm{mM})$ & $220 \pm 18 \% *$ & no activity & no activity & no activity \\
\hline $\mathrm{CuCl}_{2}(100 \mu \mathrm{M})$ & $50 \pm 20 \% *$ & no activity & no activity & no activity \\
\hline
\end{tabular}

Enzymes ( $55 \mu \mathrm{L}$ of $0.5 \mu \mathrm{g} / \mu \mathrm{L}$ LOX2, LOX3, LOX4 or $100 \mu \mathrm{L}$ of $1.0 \mu \mathrm{g} / \mu \mathrm{L}$ LOX6) were injected into LeA (30 $\mu$ M in $20 \mathrm{mM}$ HEPES pH 8.0) \pm $1 \mathrm{mM} \mathrm{MgCl} 2$ or $\mathrm{CaCl}_{2}, \mathrm{CuCl}_{2}(100 \mu \mathrm{M})$ and $\mathrm{CdSO}_{4}(1 \mathrm{mM})$. The control values of oxygen consumption in the absence of metal substitutions (nmol. $\mathrm{mL}^{-1} \cdot \mathrm{min}^{-1}$ ) were as follows. LOX2: $2.3 \pm 0.3$, LOX3: $13.8 \pm 1.0$, LOX4: $20.0 \pm 1.0$, LOX6: $1.8 \pm 0.8$. All values are means \pm SD of $\mathrm{n}$ $\geq 3$. Asterisks denote a significant difference $(p<0.05)$ in comparison to the control (post hoc Tukey HSD).

The activity of 13-LOXs was abolished (LOX3, LOX4, LOX6) or strongly decreased (LOX2) by the addition of $100 \mu \mathrm{M} \mathrm{Cu}^{2+}$.

In contrast to the inhibition of $\mathrm{LOX} 3,4$ and 6 in the presence of $1 \mathrm{mM} \mathrm{CdCl}_{2}$, the rate of oxygen consumption increased when LOX2 was injected into LeA supplemented with 
$1 \mathrm{mM} \mathrm{Cd}^{2+}$ (Table 2). The concentration dependency of $\mathrm{Cd}^{2+}$ on LOX2 activity was analyzed spectrophotometrically (Figure S6B), revealing the following values $\left(\mathrm{nmol} \cdot \mathrm{s}^{-1} \cdot \mathrm{mg}^{-1}\right.$, mean \pm SD of $n \geq 3$ ): $0.8 \pm 0.2$ for control, $2.3 \pm 0.3$ in the presence of $40 \mu \mathrm{MCd}^{2+}, 5.2 \pm 0.9$ in $150 \mu \mathrm{M} \mathrm{Cd}^{2+}$ and $5.7 \pm 0.7$ in $1180 \mu \mathrm{M} \mathrm{Cd}^{2+}$. With regard to applications, e.g., for the optimization of 13-LOX activity in 12-OPDA synthesis, we were interested in exploring whether 13-LOXs are also activated when lysed in buffer without supplements, as utilized in 12-OPDA synthesis (see Section 4.8). As suggested from the dialyzed LOX2 lysate, all 13-LOXs except LOX2 were inhibited by $\mathrm{Cd}^{2+}$, whereas $\mathrm{Ca}^{2+}$ or $\mathrm{Mg}^{2+}$ stimulated LOX3 and LOX6 activity, in line with Table 2 (see Table S3).

The next assay addressed the hypothesis that 13-LOX may be inhibited by its product 12-OPDA, as one possible mechanism of feedback regulation. We incubated 12-OPDA with 13-LOXs and analyzed the results for the remaining LOX activity. The non-physiological Michael acceptor N-ethylmaleimide (NEM) was also included as a control to support any observations made with MJ and 12-OPDA. As seen in Table 3, a decrease in LOX activity occurred in the presence of 12-OPDA, which was less pronounced with the 12-OPDA-derivative MJ. MJ was also tested to reveal insights into the selectivity and feedback modulatory aspects: (i) the cyclopentanone-like-prostaglandin is a model jasmonatelike compound devoid of $\alpha, \beta$-unsaturated carbonyl system, unique to Michael acceptors (for more details, see [37]); (ii) MJ was revealed to enhance the transcription of LOX2 and LOX3 (see Section 3.5). In several systems, endogenous JA accumulation is inhibited by the application of salicylic acid (SA) to plants [19]. Therefore, we also explored whether this phytohormone, in addition to the LOX-HPL-derived TA, affects 13-LOX activity in vitro. The first tests did not result in any significant effects of SA and TA on LOX activity. To augment these observations, LOX activity was spectrophotometrically assayed in presence of reactive molecules. Due to the 10-fold higher sensitivity of detection [38], we used less enzyme but kept the same compound concentrations of $280 \mu \mathrm{M}$ and $4.8 \mu \mathrm{M}$ LeA. Here, NEM, 12-OPDA and MJ (except for LOX4) diminished LOX activity more intense, whereas the effects of the other tested chemicals on 13-LOX were in the same range as recorded polarographically (see Table 3).

Table 3. The effect of various chemicals on 13-LOX activity.

\begin{tabular}{|c|c|c|c|c|}
\hline \multirow{2}{*}{ Polarography } & \multicolumn{4}{|c|}{ Relative Activity (\%) } \\
\hline & LOX2 & LOX3 & LOX4 & LOX6 \\
\hline NEM & $84 \pm 4 \%$ * & $51 \pm 6 \%$ * & $11 \pm 3 \%$ * & $47 \pm 15 \%$ * \\
\hline 12-OPDA & $64 \pm 4 \% *$ & $60 \pm 5 \%$ * & $21 \pm 5 \% *$ & $50 \pm 10 \%$ * \\
\hline MJ & $87 \pm 10 \%$ * & $85 \pm 5 \%$ * & $95 \pm 3 \%$ & $94 \pm 6 \%$ \\
\hline TA & $95 \pm 8 \%$ & $100 \pm 5 \%$ & $100 \pm 9 \%$ & $101 \pm 12 \%$ \\
\hline SA & $96 \pm 7 \%$ & $101 \pm 5 \%$ & $101 \pm 4 \%$ & $103 \pm 5 \%$ \\
\hline \multirow{2}{*}{ Photometry } & \multicolumn{4}{|c|}{ Relative activity (\%) } \\
\hline & LOX2 & LOX3 & LOX4 & LOX6 \\
\hline NEM & $35 \pm 10 \%$ * & $29 \pm 10 \%$ * & $3 \pm 2 \%$ * & $13 \pm 2 \%$ * \\
\hline 12-OPDA & $49 \pm 10 \%$ * & $35 \pm 5 \%$ * & $6 \pm 4 \% *$ & $59 \pm 10 \%$ * \\
\hline MJ & $62 \pm 10 \%$ * & $60 \pm 4 \%$ * & $99 \pm 7 \%$ & $86 \pm 6 \%$ * \\
\hline TA & $105 \pm 5 \%$ & $103 \pm 4 \%$ & $106 \pm 4 \%$ & $100 \pm 9 \%$ \\
\hline SA & $100 \pm 8 \%$ & $106 \pm 5 \%$ & $103 \pm 8 \%$ & $100 \pm 9 \%$ \\
\hline
\end{tabular}

Upper table, polarographic recordings. LOX6: $90 \mu \mathrm{L}(1.0 \mu \mathrm{g} / \mu \mathrm{L})$ was incubated with $10 \mu \mathrm{L} 2.8 \mathrm{mM}$ chemicals or solvent, LOX2, LOX3: LOX4: $45 \mu \mathrm{L}(0.5 \mu \mathrm{g} / \mu \mathrm{L})$ were incubated with $5 \mu \mathrm{L} 2.8 \mathrm{mM}$ chemicals or solvent and injected into $1.8 \mathrm{~mL} \mathrm{LeA}(30 \mu \mathrm{M} \mathrm{in} 50 \mathrm{mM} \mathrm{Tris-HCl}$, $\mathrm{pH}$ 7.2). Values of oxygen consumption ( $\left.\mathrm{nmol} \cdot \mathrm{mL}^{-1} \cdot \mathrm{min}^{-1}\right)$ are means $( \pm \mathrm{SD}$ of $\mathrm{n} \geq 3$ ), and the control values were: LOX2: $3.6 \pm 0.6, \mathrm{LOX} 3$ : $14.6 \pm 1.0$, LOX4: $18.6 \pm 3.0$, LOX6: $2.8 \pm 0.7$. Lower table, photometric recordings. Enzymes $(0.225 \mu \mathrm{g} / \mu \mathrm{L})$ were incubated $(10 \mathrm{~min}$ at $30^{\circ} \mathrm{C}$ ) with $280 \mu \mathrm{M}$ chemicals or solvent $(0 \mu \mathrm{M}$, control) and injected $(3 \mu \mathrm{L})$ into $123 \mu \mathrm{L} \mathrm{LeA}(4.8 \mu \mathrm{M}$ in $50 \mathrm{mM}$ Tris- $\mathrm{HCl}, \mathrm{pH} 7.2)$. Here, $100 \%$ refers to the control activity. Values of conjugated diene formation were measured at $234 \mathrm{~nm}\left(\mathrm{nmol} \cdot \mathrm{s}^{-1} \cdot \mathrm{mg}^{-1}\right)$ and are means $(\mathrm{n} \geq 3 \pm \mathrm{SD})$. Control values: LOX2: $1.7 \pm 0.2$, LOX3: $33.1 \pm 2.0$, LOX4: $37.0 \pm 2.0$, LOX6: $2.5 \pm 0.3$. Asterisks denote a significant difference $(p<0.05)$ in comparison to the control (post hoc Tukey HSD). 
We concluded that of the three compounds derived from 13-LOX, only MJ and 12-OPDA were inhibitory on LOX activity, supporting a model of feedback inhibition. To gain additional biochemical information, we aimed at determining enzyme inhibitory constants. Furthermore, we analyzed whether MJ and 12-OPDA alter the LOX protein conformation, which is often accompanied by protein functional changes [33]. Incubation of LOX4 $(0.22 \mu \mathrm{g} / \mu \mathrm{L})$ with indicated amounts of chemicals revealed the inhibition of LOX4 by 12-OPDA, with an $\mathrm{IC}_{50}$ value of $48 \pm 3 \mu \mathrm{M}$ (Figure $5 \mathrm{~A}$ ). Incubation of LOX2, LOX3 and LOX6 with 12-OPDA revealed that a level of $108 \mu \mathrm{M}$ significantly $(p \leq 0.05)$ decreased their activities in comparison to the control (see Figure S7A). An $\mathrm{IC}_{50}$ value of $130 \pm 31 \mu \mathrm{M}$ was estimated for LOX3. Due to the effects of $\mathrm{pH}$, reliable $\mathrm{IC}_{50}$ values could not be derived for LOX2 and LOX6; however, as inferred from the dose-response curves and data shown in Table 3 , these $\mathrm{IC}_{50}$ values likely range between 280 and $338 \mu \mathrm{M}$.

A

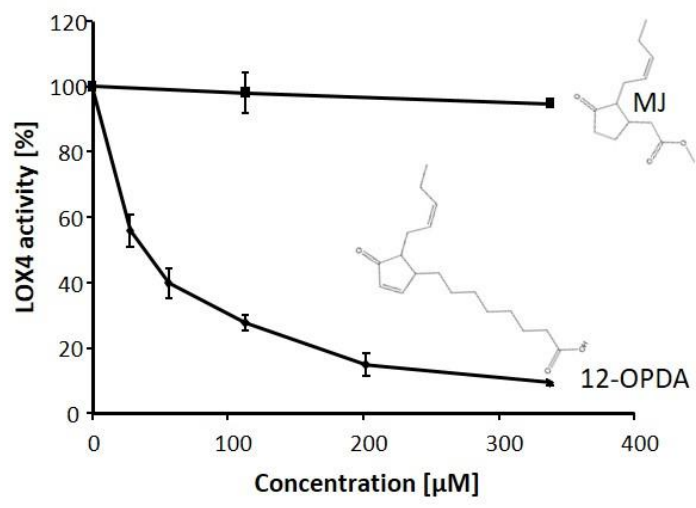

B

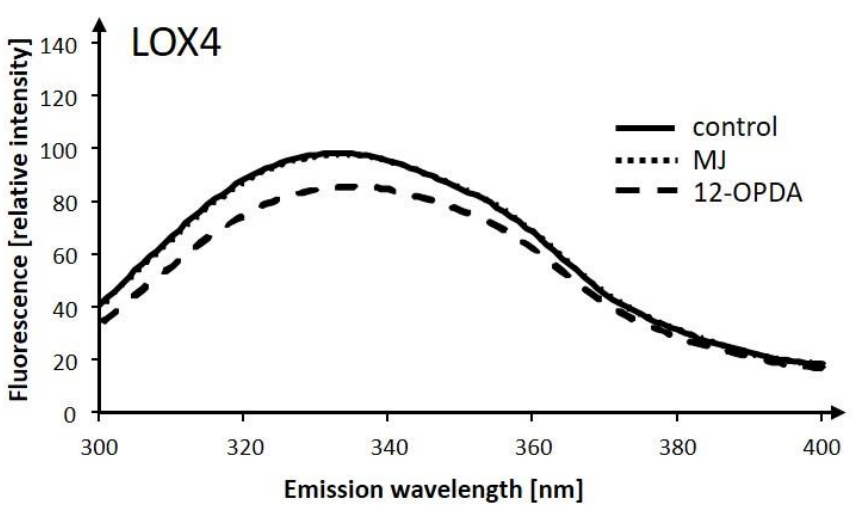

Figure 5. Analysis of the interaction of 12-OPDA and MJ with LOX4. (A) Dose-dependent inhibitory effects of 12-OPDA and MJ on the activity of LOX4. LOX4 $(0.22 \mu \mathrm{g} / \mu \mathrm{L})$ was incubated with compounds at indicated concentrations for $10 \mathrm{~min}$ at $30^{\circ} \mathrm{C}$, and residual LOX activity was measured spectrophotometrically by the injection of $3 \mu \mathrm{L}$ incubation mixture into $123 \mu \mathrm{L}$ LeA $(4.8 \mu \mathrm{M}$ in $50 \mathrm{mM}$ Tris- $\mathrm{HCl}, \mathrm{pH} 7.2)$. Values $\left(\mathrm{nmol} \cdot \mathrm{s}^{-1} \cdot \mathrm{mg}^{-1}\right.$, means $\pm \mathrm{SD}(\mathrm{n}=3)$ ) are given relative to LOX4 activity (38.0 \pm 2.0$)$ obtained with solvent (control). (B) Intrinsic fluorescence of LOX4 incubated with 12-OPDA, MJ and solvent (control). Here, $120 \mu \mathrm{L} \mathrm{LOX} 4(0.2 \mu \mathrm{g} / \mu \mathrm{L})$ was mixed with $15 \mu \mathrm{L}$ chemical $(1.4 \mathrm{mM}$ in $50 \mathrm{mM} \mathrm{K-Pi,} \mathrm{pH} \mathrm{8.0)} \mathrm{or} \mathrm{solvent}$ (control) and analyzed for intrinsic fluorescence emission after excitation at $\lambda_{\mathrm{Exc}}=280 \mathrm{~nm}$. Mean graphs are shown $(\mathrm{n}=4)$.

Intrinsic fluorescence studies of LOX4 (see Figure 5B) revealed a decrease in fluorescence emission in the presence of $156 \mu \mathrm{M}$ 12-OPDA. At the LOX4 fluorescence emission maxima of $333 \mathrm{~nm}\left(\lambda_{\mathrm{Exc}}=280 \mathrm{~nm}\right)$, which was not altered by the indicated chemicals, the relative fluorescence emission mean values $( \pm$ SD of $n=4)$ were as follows: $98.1 \pm 3.9$ (control), $86.2 \pm 3.9$ (12-OPDA), $98.0 \pm 2.4$ (MJ). Thus, a change in the intrinsic fluorescence of LOX4 was not observed when incubated with MJ. Unlike LOX4, MJ altered the intrinsic fluorescence of LOX2 and LOX3 and, as observed by photometry, the activity decreased by more than $40 \%$ at $280 \mu \mathrm{M} \mathrm{MJ}$ (see Table 3 and Figure S7B) in comparison to $7 \%$, as observed for LOX4 at $338 \mu \mathrm{M}$ (see Figure 5A). To further evaluate the mechanism of inhibition of 13-LOXs by MJ and 12-OPDA on 13-LOXs, kinetic studies were undertaken. MichaelisMenten plots and the corresponding Lineweaver-Burk double reciprocal plots at increasing inhibitor and substrate concentrations are presented in Supplementary Figures S8-S10. The Lineweaver-Burk plot of 12-OPDA against LOX2 revealed a decrease in the velocity of the reaction when the enzyme was saturated by substrate at apparent Vmax-values. Together with the change in the apparent Michaelis-Menten-constant, 12-OPDA tested at $226 \mu \mathrm{M}$ was consistent with a non-competitive mode of LOX2-inhibition. As for MJ, the intersecting lines on the $y$-axis were only slightly changed, whereas the slope was increased in comparison to control and 12-OPDA incubates. The result is in line with a competitive effect of the cyclopentanone on LOX2.

As for LOX6, the identified inhibitor 12-OPDA was non-competitive at concentrations of $226 \mu \mathrm{M}$ (see Figure S8). As for LOX3, MJ only minimally affected the apparent Km-values, 
ranging between $10 \mu \mathrm{M}$ and $11 \mu \mathrm{M}$, in comparison to the control (no effector present) value of $11 \mu \mathrm{M}$, observed with a Lineweaver-Burk plot, and $9 \mu \mathrm{M}$ with Michaelis-Menten plot. The apparent Vmax values declined from $66 \mu \mathrm{M}$ (control) to $39 \mu \mathrm{M}$, with increasing MJ. The Dixon plot for MJ produced intersecting lines on the $x$-axis, confirming the non-competitive mode of inhibition and providing a Ki value of $295 \mu \mathrm{M}$ (Figure 6A). In short, 12-OPDA acted in a non-competitive or mixed mode. As seen in the respective Michaelis-Menten and Lineweaver-Burk-plots, both the apparent Vmax and Km-values were affected. The Dixon plot (Figure 6B) was in line with a noncompetitive mode of inhibition, with an estimated Ki-value of $13 \mu \mathrm{M}$, which is in disagreement with the titrated $\mathrm{IC}_{50}$-value of $130 \mu \mathrm{M}$. As for LOX4, the Dixon plot revealed a Ki-value of $10 \mu \mathrm{M}$, similar to that of the observed $\mathrm{IC}_{50}$ value (Figure 6C).
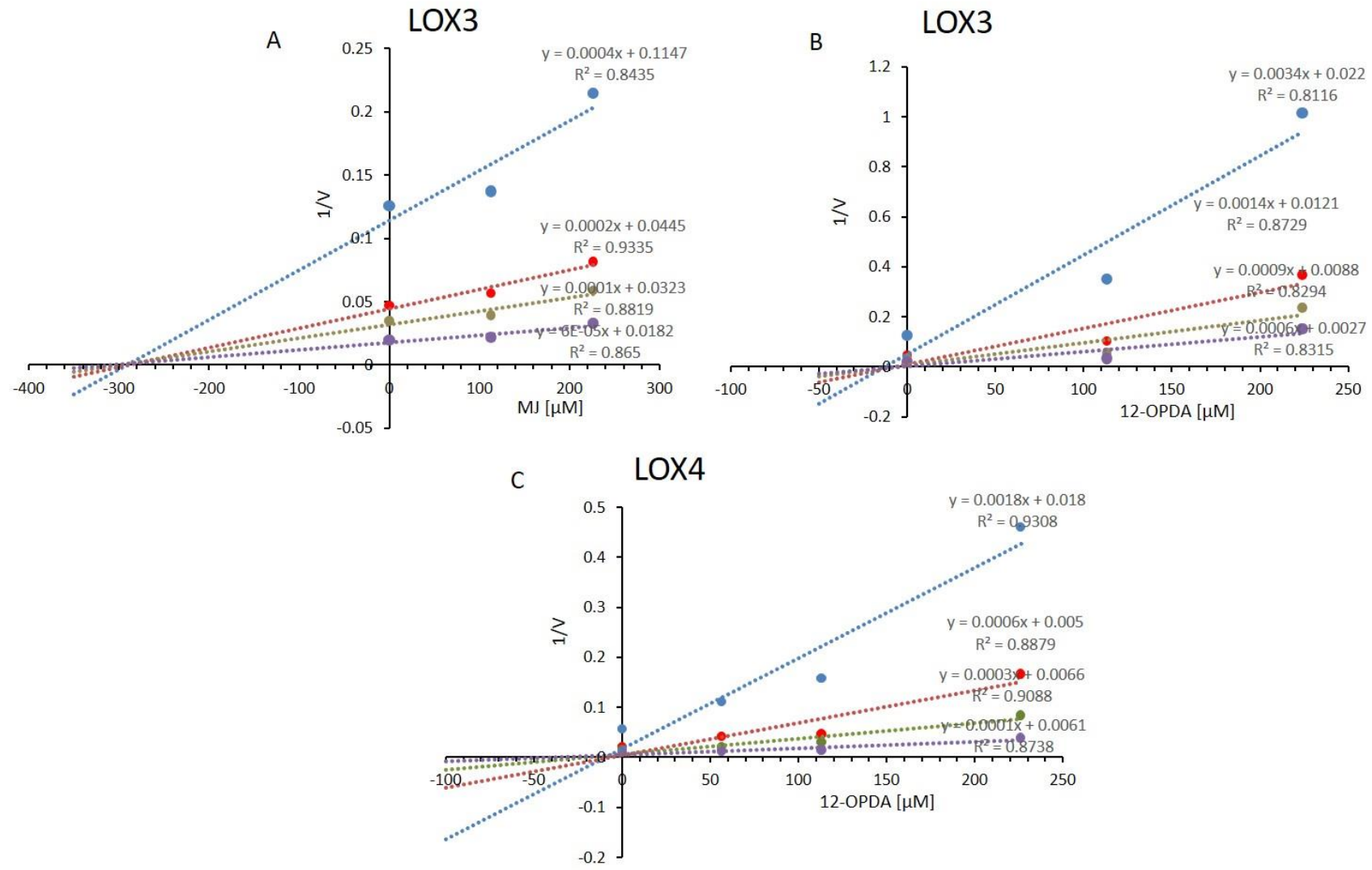

Figure 6. Dixon plots for the inhibition of LOX3 by MJ (A) and 12-OPDA (B) and LOX4 by 12-OPDA (C) Blue symbols and fitted straight lines represent enzyme activity with $1.6 \mu \mathrm{M}$ substrate, while red, green and violet represent enzyme activities with $4.8 \mu \mathrm{M}, 12.8 \mu \mathrm{M}$ and $25.6 \mu \mathrm{M}$ LeA. As for LOX4, blue symbols and fitted straight lines represent enzyme activity with $1.6 \mu \mathrm{M}$ substrate, while the red, green and violet represent enzyme activities with $9.6 \mu \mathrm{M}, 16 \mu \mathrm{M}$ and $32 \mu \mathrm{M}$ LeA. Analysis of pre-incubated protein $(0.22 \mathrm{mg} / \mathrm{mL})$, at $30^{\circ} \mathrm{C}$ (control, solvent of 12-OPDA or MJ), was performed as described in Section 4.6. Values were obtained from the data presented in Figures S9 and S10.

By considering the Michaelis-Menten curves (Figure S10A), where I = Ki would reveal half-maximal activity for noncompetitive inhibition, the value of $10 \mu \mathrm{M}$ seems overestimated. The Lineweaver-Burk plot revealing a decrease in apparent $\mathrm{V}_{\max }$ - and an increase in apparent $\mathrm{Km}$-values, together with the Dixon plot, supported the conclusion that 12-OPDA was either a non-competitive or mixed LOX4 inhibitor. Slight decreases in apparent $V_{\max }$ values might be due to minor variations in enzyme quality or the pre-incubation procedure at $30^{\circ} \mathrm{C}$, as the activities of 13 -LOXs decrease at elevated temperatures. LOX6 was most sensitive, as depicted by the half-life values in Figure S11.

To translate our findings on the impacts of 12-OPDA on 13-LOX to in vivo conditions, we assayed root and leaf extracts from $A$. thaliana for LOX activity with no positive results, as was in line with previous reports [39]. An alternative source of 13-LOX is 
the dicot vegetable pea [40]. We detected pea LOX protein by antibody staining and activity in enzyme tests in young roots; that is, the organ depleted of LOX inhibitors, in contrast to leaves [41] (Figure S12). The oxygen-electrode recording with $36 \mu \mathrm{g}$ pea root extract, pretreated with $1 \mathrm{mM} 12-\mathrm{OPDA}$, revealed an inhibition of activity by about $43 \%$ $\left(2.0 \pm 0.5 \mathrm{nmol} \cdot \mathrm{mL}^{-1} \cdot \mathrm{min}^{-1}, \mathrm{n}=4\right)$ relative to the control $\left(4.6 \pm 0.5 \mathrm{nmol} \cdot \mathrm{mL}^{-1} \cdot \mathrm{min}^{-1}\right.$, $\mathrm{n}=4$ ). Thus, 12-OPDA may also inhibit 13-LOX in vivo.

\subsection{The Role of Cysteine Residues in Activity Regulation of AtLOX4}

To analyze whether cysteinyl thiols of 13-LOX are involved in activity regulation, we focused on LOX4. At first, we were interested in whether OPDA covalently modifies the cysteines of LOX4, and whether this type of reaction might be the reason for activity impairment. Here, we determined its free thiol content using the method adopted by Ellman (Figure 7A). Essentially, all eight Cys residues (Figure 1B; $7.6 \pm 0.1 \mathrm{~mol} \cdot \mathrm{mol}^{-1}$, $\mathrm{n}=4$ ) were detected in the reduced state. After incubation with 12-OPDA, six Cys residues $(5.9 \pm 0.1, \mathrm{n}=4)$ remained, suggesting that $1-2$ reactive thiols are involved in LOX4 activity modulation by 12-OPDA. GSH potentially reacts with 12-OPDA in a nucleophilic addition reaction and could decrease or even abolish 12-OPDA reactivity. To reveal whether the thiol antioxidant GSH protects 13-LOX from inactivation by the cysteine-reactive 12-OPDA, we incubated $12.2 \mu \mathrm{g}$ LOX4 with $1.3 \mathrm{mM} \mathrm{GSH}$, prior to the addition of $140 \mu \mathrm{M}$ 12-OPDA, and analyzed the results for residual activity. In comparison to the control (LOX4: $9.8 \pm 0.1 \mathrm{nmol} \cdot \mathrm{mL}^{-1} \cdot \mathrm{min}^{-1} \hat{=} 100 \%, \mathrm{n}=2$ ), GSH showed a minor protective effect on LOX4 against 12-OPDA, namely, by $\sim 7.1 \%\left(3.6 \pm 0.1 \mathrm{nmol} \cdot \mathrm{mL}^{-1} \cdot \mathrm{min}^{-1} \hat{=} 36.7 \%, \mathrm{n}=2\right)$ compared to incubation with $12-\mathrm{OPDA}$ alone $\left(2.9 \pm 0.1 \mathrm{nmol} \cdot \mathrm{mL}^{-1} \cdot \mathrm{min}^{-1} \hat{=} 29.6 \%, \mathrm{n}=2\right.$; see Figure 7B).

A

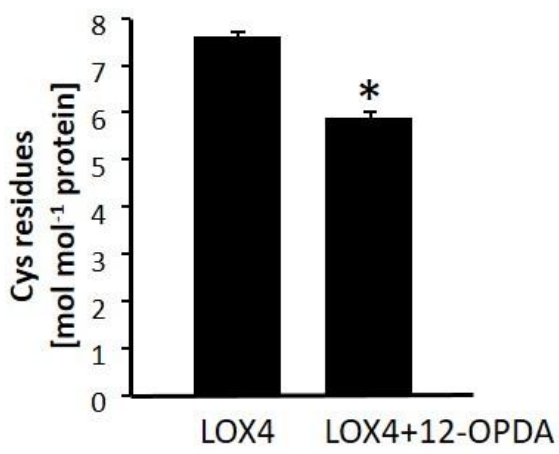

B

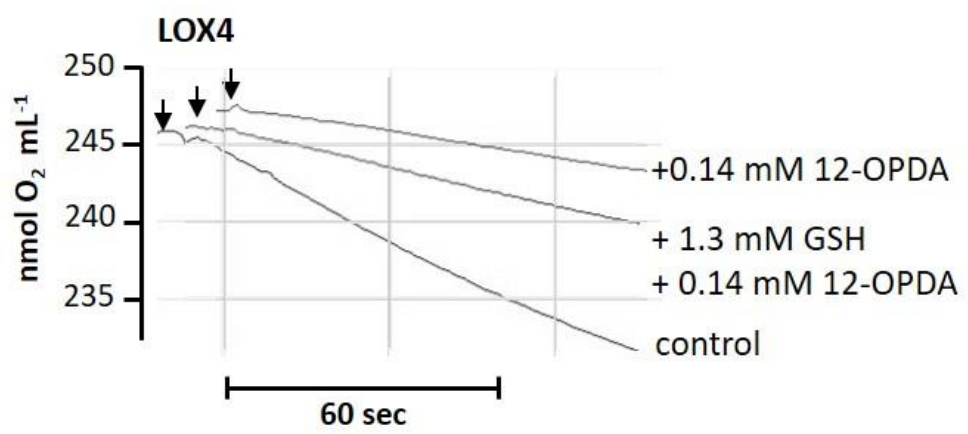

Figure 7. Involvement of thiols in the interaction of LOX4 with 12-OPDA. (A) Free thiols of LOX4 incubated with 12-OPDA. Asterisks indicate a significant difference $(p \leq 0.05)$ in comparison to control incubate (12-OPDA solvent), calculated using one-way ANOVA with post hoc Tukey HSD. (B) $\mathrm{O}_{2}$-electrode recordings on the effect of GSH on the efficacy of the herein-identified LOX inhibitor 12-OPDA. GSH or GSH solvent (40 mM K-Pi, pH 8.0) was pre-incubated for 5 min with LOX4 before 12-OPDA as indicated by the arrows was added to the mixture. After $10 \mathrm{~min}$, the incubation mixture was injected into $1.8 \mathrm{~mL} 20 \mu \mathrm{M}$ LeA at $25^{\circ} \mathrm{C}$. The recording of LOX4 incubated with $40 \mathrm{mM} \mathrm{K}-\mathrm{Pi}, \mathrm{pH} 8.0$ and solvent is shown as a control. The three recordings were performed thrice with the same result.

Inhibition remained almost unchanged after doubling the LOX4 concentration. In this case, GSH was protected by $\sim 11.7 \%$ (LOX4: $19.7 \pm 0.1 \mathrm{nmol} \cdot \mathrm{mL}^{-1} \cdot \mathrm{min}^{-1} \hat{=} 100 \%$, $\mathrm{n}=4$, LOX $4+140 \mu \mathrm{M} 12$-OPDA: $6.7 \pm 0.1 \mathrm{nmol} \cdot \mathrm{mL}^{-1} \cdot \min \hat{=} 34 \%, \mathrm{n}=2, \mathrm{LOX} 4+1.3 \mathrm{mM}$ $\mathrm{GSH}+140 \mu \mathrm{M}$ 12-OPDA: $9.0 \pm 0.1 \mathrm{nmol} \cdot \mathrm{mL}^{-1} \cdot \mathrm{min}^{-1} \hat{=} 45.7 \%, \mathrm{n}=2$ ). In addition, a twofold increase of GSH concentration failed to protect LOX (LOX4 + 2.6 mM GSH + $140 \mu \mathrm{M}$ 12-OPDA $8.5 \pm 0.6 \mathrm{nmol} \cdot \mathrm{mL}^{-1} \cdot \mathrm{min}^{-1}, \mathrm{n}=3$ ). Only the extended pre-incubation of 12-OPDA with GSH protected LOX4 from inactivation by 12-OPDA (see Figure S13), demonstrating that the electrophilic $\alpha, \beta$-unsaturated carbonyl system of 12-OPDA is likely to be involved in the inhibition of LOX4 activity caused by 12-OPDA. 
The PLAT domain is involved in LOX activity regulation. In human hLOX5, the PLAT domain is the reaction site of inhibiting Michael systems [42,43]. Sequence alignment of the mentioned LOXs and annotated plant 13-LOXs revealed that two cysteine residues in the respective PLAT domain partially align (Figure 8A). The thiol-bearing F-C-W motif is involved in the stability and catalysis of LOXs $[24,25]$ and is absent in LOX6. Furthermore, the N-terminal Cys203 of LOX4 is also present in hLOX12 in other plant LOX, e.g., Zea mays, and in PLAT 1-3. Among the At-13-LOXs, LOX4 displays the highest sequence identity with hLOXs, this being $26.43 \%$ and $27.34 \%$ to LOX5 and LOX12 (supplementary File S1).

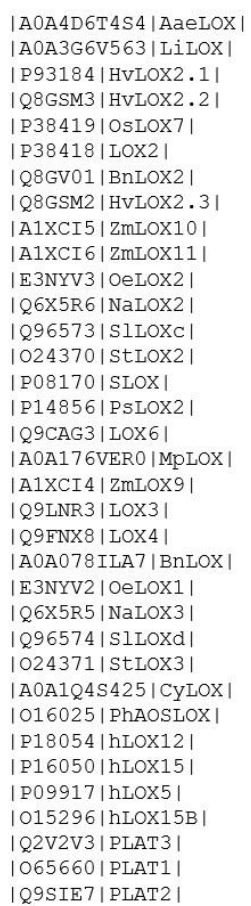

B

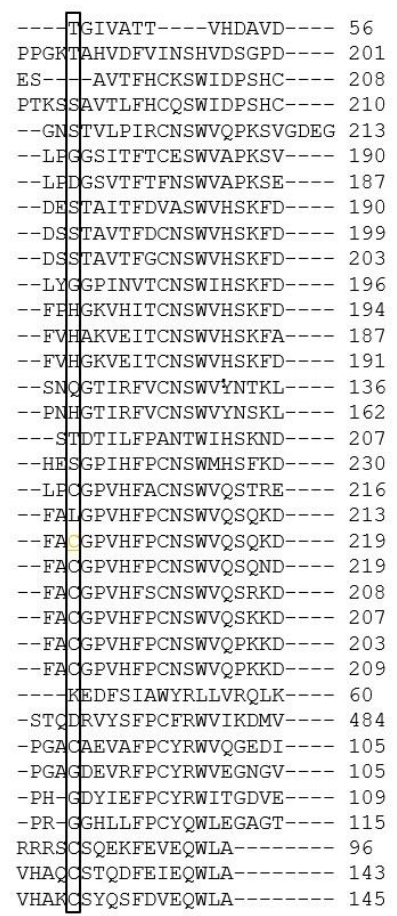

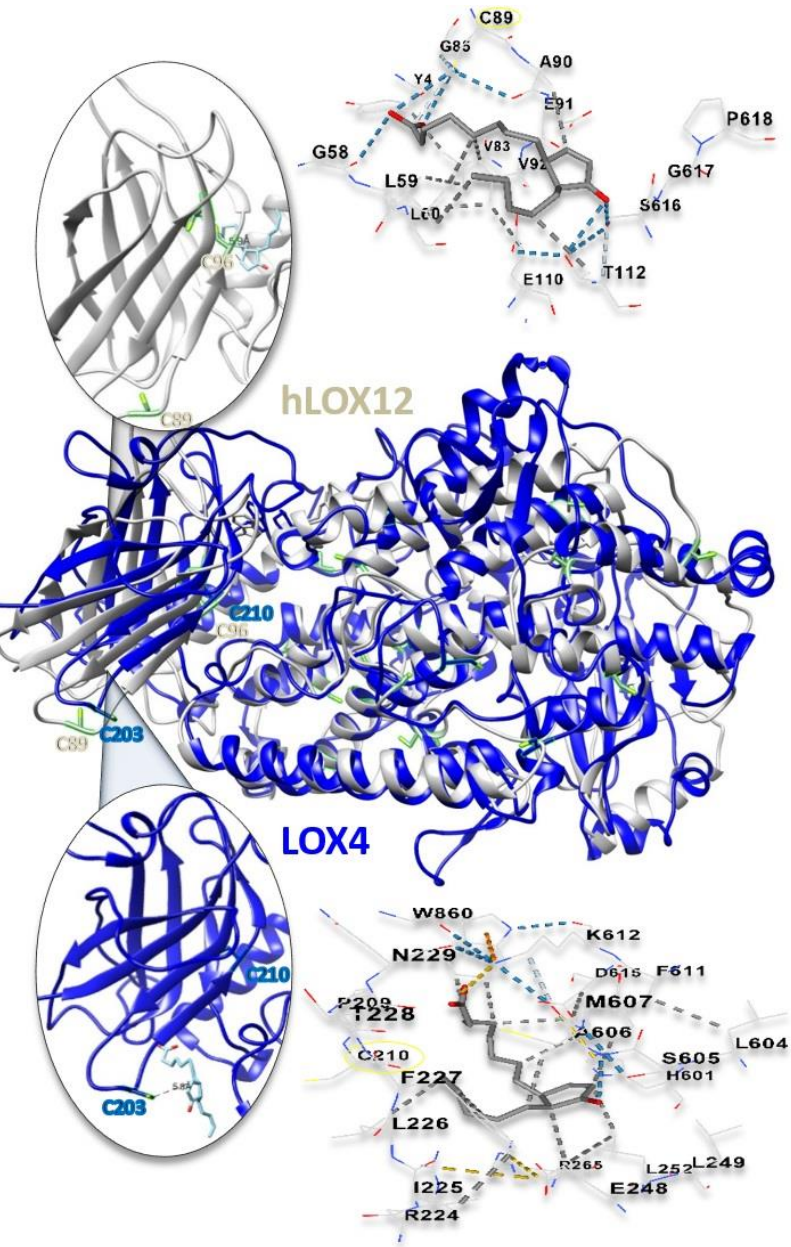

Figure 8. In silico analysis of LOX4, related proteins, and their interaction with the 12-OPDA. (A) Cys203 locates in the PLAT domain of LOX4 and is present in hLOX12, PLAT proteins and plant 13-LOXs, as revealed by multiple sequence alignment (not fully shown) with LOXs from fungi (Agrocybe aegerita, Aae), algae (Lobosphaera incisa, Li), cyanobacteria (Calothrix sp. HK-06, Cy), moss (Marchantia polymorpha, Mp), anthozoa (Plexaura homomalla, Ph), monocot (Oryza sativa, Os, Zea mays, Zm, Hordeum vulgare, Hv) and dicot plants (Glycine max, S, Brassica napus, Bn, Olea europaea, Oe, Pisum sativum, Ps, Nicotiana attenuata, Na, Solanum lycopersicum, Sl, Solanum tuberosum, St) and humans (h). Codes represent Uniprot/SwissProt IDs. (B) Structural alignment of LOX4 with LOX12, and blind docking studies with LOX4 and hLOX12, revealed that PLAT Cys (shown as sticks) are similarly positioned $(<6 \AA$ ) and are addressed by 12 -OPDA, with distances not exceeding $6 \AA$ (shown as a blue and grey stick model). The models were obtained by in silico studies with Swiss Dock and CB-DOCK online tools. One of the top 10 and top 5 possible docking modes is presented. LOX domains are not fully shown. The remaining Cys residues and the LOX stabilizing interaction between LOX4Trp213 and LOX4Arg327, Trp99 and Arg165 in hLOX12 are also presented with side-chains highlighted.

Structural alignment of LOX4 with LOX12 predicts that the Cys residues of the PLAT domain are located at similar positions. Furthermore, blind docking studies employing the CB-DOCK and Swiss Dock online tools revealed interdomain interaction 
with 12-OPDA (Figure 8B), similar to that reported for hLOX5 with 3-acetyl-11-keto-betaboswellic acid [43]. Based on these results with LOX4, namely, its sensitivity to thiol modifications, the intrinsic fluorescence change, and in silico analyses, it appeared that C203 might be involved in activity regulation. Therefore, C203 of LOX4 was replaced with Ser by site-directed mutagenesis. Unfortunately, we were unsuccessful in obtaining the site-directed variant of 13-LOX as immunoreactive heterologously expressed protein (data provided on request).

\section{Discussion}

\subsection{Synthesis of Functional 13-LOX Isoforms}

In this study, Arabidopsis 13-LOXs could be obtained from an E. coli protein expression system, previously derived from an insect expression system used by Bannenberg et al. [12] Despite the disadvantage of utilizing partially purified proteins for biochemical characterizations, the data presented herein extend the molecular characteristics of At-LOX, first provided by Bannenberg et al. [12]. Difficulties in the synthesis of functional 13-LOX or hLOXs were observed in previous studies and the utilization of enzyme-containing lysates or partially purified LOXs is not unusual $[12,14,44,45]$ when gaining the biochemical characteristics of LOXs. The iron loads and enzyme purities of 13-LOXs were not taken into consideration in the determination of activity characteristics; thus, the activities are apparent values that might alter if isolated with iron loads of $100 \%$ and increased purities, especially for LOX6. Their apparent $\mathrm{K}_{m}$ and $\mathrm{V}_{\max }$ activity values with the favored substrates, LA or LeA, are similar when compared to the 13-LOXs of other plant sources, for example, tomato, banana, melon and soybean, with values between 1.4 and $200 \mu \mathrm{M}[21,46,47]$ and hLOXs [48].

\subsection{Subcellular Localization of 13-LOX Isoforms}

Arabidopsis 13-LOXs and orthologs are predicted to be located in plastids [2,12,15]. This was previously indicated in proteomics studies for LOX2 and LOX6 [49]. Accordingly, the putative transit peptide (Figure 1A) of each $A$. thaliana 13-LOX isoform was sufficient to target YFP to the chloroplasts in transfected protoplasts (Figure 2); thus, 13-LOXs are likely to reside in plastids. However, it is likely that 13-LOXs locate to non-photosynthetic organelles as well, as shown for the LOX6 and LOX2 that were also identified in root plastids [17] and nucleus [50].

\subsection{Substrate Specificities and Evolutionary Relations}

As reported in [12], LOX3, LOX4 and LOX6 were maximally active at neutral pH ( $\mathrm{pH}$ 7.2). In slight contrast to our data, [12] reported LOX2 activities below $50 \%$ with LA $(\sim 40 \%)$ and ARA ( 15\%) and revealed no pH optimum. This might be due to different methods for protein and substrate preparation. Our observation of LOX2, as being an enzyme with good peroxidation activity toward ARA and LA, fits into its evolutionary relatedness to potato LOX2 (O24370) and the rice leaf pathogen-inducible lipoxygenase (OsLOX7, P38419), shown to have similar activities toward ARA and LA [31,51]. The identification of $\omega-6$ DHA peroxidation might indicate that LOX2 is closer to hLOX15 than to hLOX12, which is also corroborated by their sequence similarities of $26.99 \mathrm{vs} .25 .55 \%$ (See Supplementary File S1). LOX15 acts as $\omega-6$ LOX toward both LeA and DHA. The 3D modeling and the protein alignment of LOXs suggest that Pro residues (P769 and P796 in LOX3 and 4) are present in the active site and, together with Cys 203 (according to LOX4), could play decisive roles in differentiating LOX3/4 from LOX2/6 functional characteristics in plants. The lack of these particular prolyl and cysteinyl residues assigns these 13-LOX to a group different from LOX3 or LOX4 (see Figure 1), e.g., AtLOX2 and StLOX2, in contrast to AtLOX4, with StLOX3 (O24371), as explored in Supplementary File S1. 


\subsection{Differential Impact of Divalent Cations on 13-LOX Isoforms}

Apart from the above outlined enzymatic characteristics, clear differences were also observed for 13-LOX sensitivity to alkaline earth metals, as previously hypothesized by [52]. LOX2 and LOX6 were strongly activated by $\mathrm{Ca}^{2+}$ and $\mathrm{Mg}^{2+}$, whereas LOX4 and LOX3 were only moderately or not activated by these ions. Whether this is due to the high number of acidic residues (Figure 1B) that often bind $\mathrm{Ca}^{2+}$ and $\mathrm{Mg}^{2+}$ [53] or owing to $\mathrm{Ca}^{2+} / \mathrm{Mg}^{2+}$-binding motifs, as observed for human LOXs [25], awaits elucidation (see Supplementary File S1). In planta, $\mathrm{Cd}^{2+}$ and $\mathrm{Cu}^{2+}$ affect the oxylipin blend [54] and abundance of 13-LOX transcripts $[55,56]$. We report that 13-LOXs are all inhibited by $\mathrm{Cu}^{2+}$, while $\mathrm{Cd}^{2+}$ stimulated LOX2 activity, similar to $\mathrm{Ca}^{2+}$ (Table 2). $\mathrm{Ca}^{2+}$ and $\mathrm{Cd}^{2+}$ have partly similar properties [53]. These in vitro data may provide an explanation for the earlier findings of Montillet et al. [57], who observed that $\mathrm{Cd}^{2+}$ increased the content of 13-HPOT in $A$. thaliana and might relate to the specific activation of LOX2 by $\mathrm{Cd}^{2+}$ in vivo.

\subsection{Suicide Inhibition and Feedback Regulation}

$\mathrm{Wu}$ [58] and Conrad [59] reported some sort of catalytic self-inhibition of SLOX and hLOX12/15 by their substrates. Likewise, we noted the enzyme inhibition of LOX3, LOX4 and LOX6 when incubated with LA or LeA, at concentrations enabling high LOX2 activity (see Figure S6A). This might imply the PUFA-dependent regulation of the 9-LOX (LAspecific, [12]) and/or 13-LOX (LeA-specific, [12]) pathways in vivo. The results support the view that all 13-LOXs potentially channel 13-HPOT in 12-OPDA biosynthesis, as anticipated for LOX6 in leaves and roots, LOX2 in leaves, and LOX3 and LOX4 (shown for JA) in inflorescences and wounded leaves $[17,20,60]$.

Similar to hLOX5, hLOX12, pea and sLOXs [58,61-63], we observed that cysteinyl residues are involved in the activity of 13-LOXs, as demonstrated by inhibition with NEM. As listed in Table 3, the physiological Michael acceptor 12-OPDA likewise decreased LOX activities. This is in accordance with a model of thiol-sensitive feedback inhibition. From the dose-response curves shown in Figure 5 and Figure S7, the $\mathrm{IC}_{50}$ values were estimated both below and above $50 \mu \mathrm{M}$ 12-OPDA for 13-LOXs. The higher concentration of 12-OPDA required to inhibit LOX2, LOX3 and LOX6, in comparison to LOX4, might be due to differential 12-OPDA sensitivities.

The gene expression of LOX3, unlike LOX4, is under the control of jasmonates [20] and, like LOX2, LOX3 is induced by MJ [64,65]. It is interesting to note that MJ, a 12-OPDA derivative (for the structure, see Figure 5), more actively interacted with LOX2 and LOX3, and that LOX4 and LOX6 were insensitive to MJ. As inferred from the photometric and polarographic activity determinations (Table 3$)$, high substrate concentrations $(30 \mu \mathrm{M})$ decreased the MJ's inhibitory action, which is suggestive of a competitive inhibition mode that differs from 12-OPDA. This was confirmed by kinetic studies revealing that, except for LOX3, MJ was identified as a competitive inhibitor. It is of note that high concentrations of substrate eliminated MJ's activity on LOX3 when probed at inhibitor concentrations of $113 \mu \mathrm{M}$. This competitive characteristic was also the case for LOX6 with 12-OPDA (see Figures S8B and S9A), suggestive of a mixed mode of enzyme inhibition [66]. The types of inhibition tentatively assessed herein might be complicated and not uniform [67], but in-depth physical chemistry analysis, as performed in Mogul et al. [67], was beyond the scope of this manuscript. Next to substrate and inhibitor concentration-dependent LOX inhibition, 12-OPDA inhibited in a time-dependent manner, as shown for LOX4 (see Figure S10B). Furthermore, it was demonstrated that 12-OPDA modifies LOX4 cysteinyl thiols and inhibits LOX4, due to its electrophilic character (Figure S13B). The interaction sites and the extent of feedback inhibition by MJ and 12-OPDA on 13-LOX isoforms await clarification.

The co-expression of HPL with LOX2 and LOX3 (see ATTED II (http:/ /atted.jp/) entries, accessed on 22 May 2021) and network association with remaining LOXs (see STRING entries (https:/ / string-db.org/, accessed on 22 May 2021) might relate to additional feedback regulatory mechanisms on oxylipin synthesis, as mentioned in [19]. Our 
data reveal that TA did not influence the activities of LOX2 and its isoforms. Therefore, feedback inhibition from the HPL branch-derived TA to 13-LOX seems unlikely to occur in vivo.

\subsection{Cyclopentenone Prostaglandins as Potential LOX Inhibitors}

LOX inhibitors were reported to enhance the proteolysis of hLOX into its two domains [43], supporting the predicted docking of 12-OPDA to the inter-domain and the potential involvement of C203 in LOX4 stabilization (Figure 8). Whether 12-OPDA targets C203 or other cysteinyl thiols in PLAT domain proteins should be investigated in future studies to elucidate the specificity of protein activity regulation by 12-OPDA, as demonstrated in this study for At-13-LOXs. Effective 13-LOX, hLOX12 and hLOX5 inhibitors are reported to exhibit $\mathrm{IC}_{50}$ values below $5 \mu \mathrm{M}$ [66], qualifying 12-OPDA as a weak LOX inhibitor. However, the potential interaction of 12-OPDA or cyclopentenones related to $12-\mathrm{OPDA}$, for example, $\mathrm{PGJ}_{2}$ or $15 \mathrm{~d}_{-} \mathrm{PGJ}_{2}$, with proteins of LOX activity, such as the LOX4-related hLOX12 (see Figure 8), provide novel insights and promising perspectives. Together with the extended 12-OPDA and OCPD synthesis protocols provided herein and in the 12-OPDA derivative synthesis protocol [68], these studies are also potential starting points for future investigations.

\section{Materials and Methods}

\subsection{Data processing, Databases and Computational Studies}

Data processing, calculations and presentations were performed using Microsoft Office 2016. Statistical analyses relied on astatsa.com/OneWay_Anova_with_TukeyHSD (2016 Version, CC, Navendu Vasavada, accessed on 28 May 2021). IC 50 values were determined with the aid of the $\mathrm{IC}_{50}$ online calculator (www.aatbio.com/tools/ic50-calculator accessed on 30 May 2021). Protein sequences were retrieved from the Uniprot database (www. uniprot.org/ accessed on 14 May 2021). The prediction of chloroplast sequences, domains and physicochemical parameters of At-LOXs were obtained using ChloroP (http:/ / www. cbs.dtu.dk/services/ChloroP/ accessed on 20 April 2021), NCBI's "conserved domains" ( www.ncbi.nlm.nih.gov/Structure/cdd/wrpsb.cgi accessed on 14 May 2021) and the tools available at the Expasy bioinformatics resource portal (www.expasy.org/ accessed on 20 April 2021). The 3D models of At-LOXs were generated based on soybean 13-LOX (SLOX, PDB 4wfo), and hLOX12 was modeled based on hLOX15 (2p0m.1) by the SWISS MODEL homology-modeling server (swissmodel.expasy.org/ accessed on 14 May 2021) using default settings [69]. The quality of the models was estimated with global model quality estimation (GMQE) and QMEAN values of 0.69 and -2.97 (LOX2), 0.69 and -2.44 (LOX3), 0.76 and -2.31 (LOX4), 0.67 and -3.58 (LOX6) and 0.86 and -2.34 (hLOX12). Active site residues were identified by the alignment of 13-LOXs with LOX3, based on [20]. The finalization and depiction of structures were performed with Pymol (the PyMOL molecular graphics system, version 1.2r3pre, Schrödinger, LLC) or UCSF Chimera [70].

Blind docking was performed with Swiss docking (www.swissdock.ch/docking, accessed on 28 April 2021) [71] and CB-Dock (clab.labshare.cn/cb-dock/php/, accessed on 28 April 2021) [72], with LOX models (see above) and MOL2 files of 12-OPDA generated from Pubchem structural data files (pubchem.ncbi.nlm.nih.gov/ accessed on 28 April 2021) via open source program open Babel [73]. Multiple protein alignment was performed with Clustal Omega (www.ebi.ac.uk/Tools/msa/clustalo/, accessed on 29 April 2021) [74].

\subsection{Chemicals and Reagents}

DHA (99\%, 271,551), ARA ( $\geq 95.0 \%, 10,931)$, LeA ( $\geq 99 \%$, L2376), linoleic acid (LA) ( $\geq 99 \%$, L1376) and MJ (95\%, 392,707) were purchased from Sigma (Darmstadt, Germany). TA was obtained from Tokyo Chemicals (TCI, Tokyo, Japan). NEM, salicylic acid (as sodium salt), buffers, other chemicals and solvents were of the highest analytical grade and were obtained from Sigma, Roth (Karlsruhe, Germany) and Merck (Darmstadt, Germany). Then, 12-OPDA and OCPD were synthesized as described previously [33]. Substrates were 
prepared according to [75] by mixing equal volumes of $40 \mathrm{mM}$ PUFA stock solution (in EtOH) with $0.1 \mathrm{M} \mathrm{KOH}$ and the addition of $\mathrm{dH}_{2} \mathrm{O}$ to obtain a $2.0 \mathrm{mM}$ solution, which was further diluted as indicated.

\subsection{Subcellular Localization Studies}

The LOX2, LOX3, LOX4 and LOX6 encoding cDNAs of putative chloroplast transit peptides (see the respective TAIR (https: / / www.arabidopsis.org/ accessed on 18 March 2019) entries At3g45140, At1g17420, At1g72520 and At1g67560) were fused to the yellow fluorescent protein (YFP). These were cloned into the 35S-YFP-NosT vector using BamHI and AgeI restriction sites, which were added to the coding sequences by PCR (for primer sequences, see Supplementary Table S1). The protoplast preparation and transfection were performed as described in [76]. The subcellular distribution of the fluorescent protein was examined by confocal laser scanning microscopy (LSM 5 Exciter, Zeiss) with a CApochromat $40 \times / 1.2 \mathrm{~W}$ autocorr objective. YFP was excited at $488 \mathrm{~nm}$ and a $2 \%$ line of the argon-ion laser, and the emission was recorded with the BP 505-600-nm filter. The chlorophyll autofluorescence was detected with the LP 650-nm filter and excited at 488 $\mathrm{nm}$. The pinhole was $90 \mu \mathrm{m}$ and the pixel dwell time was $4.58 \mu \mathrm{s}$, with a line average of 4 , and images were encoded by 12-bit. Fluorescence images and spectra were analyzed with the ZEN Digital Imaging Software. The magenta color was used to code the chlorophyll fluorescence and green color for YFP.

4.4. Cloning, Expression and Preparation of Lipoxygenase Wild-Type and Variant LOX2, LOX3, LOX4, LOX6 and LOX4 C203S

The cDNAs encoding 13-LOX proteins were amplified from the RAFL cDNA clones obtained from the RIKEN Bioresource Center (https: / / web.brc.riken.jp/en/accessed on 14 May 2018) by PCR, using gene-specific primers (Supplementary Table S1). The cDNAs were cloned into the Invitrogen $\mathrm{pET15b}$ vector (Merck, Darmstadt, Germany) or Invitrogen pEXP5-NT-TOPO vector (Fisher, Schwerte, Germany; LOX6) in frame with the N-terminal His-tag and transformed into Nico21(DE3) cells (NEB) for heterologous expression in E. coli. LOX4C203S was generated with LOX4 as a template and in vitro mutagenesis primers (Supplementary Table S1). The correctness of the constructs was verified by DNA sequencing. Then, $600 \mathrm{~mL}$ Luria-Bertani medium, containing $600 \mu \mathrm{g} / \mathrm{mL}$ ampicillin, was inoculated with $50 \mathrm{~mL}$ of a non-induced overnight bacteria culture and incubated at $37^{\circ} \mathrm{C}$ and $150 \mathrm{rpm}$ to an $\mathrm{OD}_{600}$ of $0.7-0.8$. Protein expression was then induced by the addition of isopropyl- $\beta$-D-thiogalactopyranoside (IPTG) to a final concentration of $0.35 \mathrm{mM}$ and $0.1 \mathrm{mM}$ of $\mathrm{NH}_{4} \mathrm{Fe}$-(III)-citrate. Induced cultures were grown at $25^{\circ} \mathrm{C}$, with orbital shaking at $120 \mathrm{rpm}$ for $20 \mathrm{~h}$. The cultures were centrifuged at $6000 \mathrm{rpm}$ for $30 \mathrm{~min}$ at $4{ }^{\circ} \mathrm{C}$ and the harvested cell pellets were stored at $-80^{\circ} \mathrm{C}$.

For protein purification, $4 \mathrm{~mL}$ of ice-cold lysis buffer $(50 \mathrm{mM}$ Tris- $\mathrm{HCl}, \mathrm{pH} 8.0,5.0 \mathrm{mM}$ imidazole, $10 \%$ glycerol, $50 \mathrm{mM} \mathrm{NaCl}, 0.05 \mathrm{mM}$ PMSF, $0.1 \mathrm{mM}$ pepstatin, $0.1 \mathrm{mM}$ pefablock, $0.25 \mathrm{mM}$ EDTA and $2.5 \mathrm{mM}$ ß-mercaptoethanol) was added per gram of cell pellet. Cells were lysed by ultrasonication ( $30 \mathrm{~s}$ for each $\mathrm{g}$ of cell pellet, with $20 \mathrm{~s}$ pause intervals on ice; Sonicator Bandelin HD 2070, amplitude 70\%). The lysate was centrifuged (25 min, $10,000 \mathrm{rpm}, 4^{\circ} \mathrm{C}$ ) and the resulting supernatant (L) was incubated with $\mathrm{Ni}^{2+}$-NTA (equilibrated with lysis buffer) for $30 \mathrm{~min}$ at $4{ }^{\circ} \mathrm{C}$. The washing $(50 \mathrm{mM}$ Tris- $\mathrm{HCl}, \mathrm{pH} 8.0,10 \mathrm{mM}$ imidazole, $10 \%$ glycerol, $50 \mathrm{mM} \mathrm{NaCl}$ ) and elution (50 mM Tris- $\mathrm{HCl}, \mathrm{pH} 8.0,250 \mathrm{mM}$ imidazole, $10 \%$ glycerol, $50 \mathrm{mM} \mathrm{NaCl}$ ) of proteins was performed according to the manufacturer's instructions (Roth, Karlsruhe, Germany, His/Ni NTA-HP Beads (0805)) at $4{ }^{\circ} \mathrm{C}$. The purification of LOX2 via $\mathrm{Ni}^{2+}$-NTA was unsuccessful. After overnight dialysis of eluates or L at $4{ }^{\circ} \mathrm{C}$ against a 1000 -fold volume of buffer ( $50 \mathrm{mM}$ Tris-HCl, $\mathrm{pH}$ 8.0) enzymes, denoted as eluates (E) and cleared lysates $(\mathrm{Cl})$, were frozen in liquid $\mathrm{N}_{2}$ and stored at $-80^{\circ} \mathrm{C}$. Enzyme quality was checked by the dilution of proteins with Laemmli buffer without a reducing agent, heating $\left(95^{\circ} \mathrm{C}, 5 \mathrm{~min}\right)$, and separation on $7.5 \%$ SDS-PAGE, followed by Coomassie blue staining. Protein amounts were determined with a Bio-Rad assay standardized with bovine serum albumin. 


\subsection{Lipoxygenase Activity}

The LOX-catalyzed hydroperoxidation of PUFAs was assayed using two different methods. Firstly, oxygen electrode measurements were performed at $25^{\circ} \mathrm{C}$ (Oxygraph + PC-operated oxygen electrode control unit with USB 2.0 connectivity, Hansatech, Norfolk UK) with a stirring speed of $50 \mathrm{rpm}$. The electrode was calibrated as described in the manufacturer's manual. Air-saturated substrate medium ( $1.8 \mathrm{~mL}, 245 \pm 15 \mathrm{nmol} \mathrm{O}_{2} \mathrm{~mL}^{-1}$ ) was equilibrated to a constant baseline for 5 min prior to injection of the sample via a Hamilton syringe. The LOX-initiated oxygen consumption was monitored as a function of time, and the linear slope after enzyme injection was used for activity calculations. No oxygen consumption occurred when the enzyme was omitted from the injection medium. Secondly, in the spectrophotometric approach, the LOX-catalyzed epoxide formation was monitored at $234 \mathrm{~nm}\left(\varepsilon=25,000 \mathrm{~L} \cdot \mathrm{mol}^{-1} \cdot \mathrm{cm}^{-1}\right.$; [77]) (Shimadzu 2401 spectrophotometer) at $25{ }^{\circ} \mathrm{C}$. Activities were calculated from the initial linear rates. All buffers were saturated with air. Kinetic parameters were determined by adding fixed LOX amounts to 6-10 different PUFA concentrations and plotting the LOX activity (nmol hydroperoxide $\cdot \mathrm{s}^{-1} \cdot \mathrm{mg}^{-1}$ ) against substrate concentration, applying the Michaelis-Menten equation using the Microsoft Excel-Solver. All LOX incubates and buffers supplemented with metal salts were checked for unchanged $\mathrm{pH}$ values in comparison to control or salt-free buffers.

The regiospecificity of LOX-mediated DHA and ARA oxygenation was determined using the method described in [33] with minor modifications. Then, 13-LOX-expressing cell sediment ( $3 \mathrm{~g}$ ) was re-suspended in $4 \mathrm{~mL} 50 \mathrm{mM}$ Tris- $\mathrm{HCl}, \mathrm{pH}$ 8.0, and then sonicated $(2 \times 30 \mathrm{~s}, 1 \times 45 \mathrm{~s})$. Then, $50 \mathrm{mM}$ Tris-HCl, $\mathrm{pH} 8.0(4 \mathrm{~mL}), 26 \mu \mathrm{L}$ PUFA and $25 \mu \mathrm{L} \mathrm{EtOH}$ were added to the supernatant obtained by centrifugation $\left(4^{\circ} \mathrm{C}, 5500 \mathrm{rpm}, 25 \mathrm{~min}\right)$. After incubation for $25 \mathrm{~min}$ on ice, lipid extraction was performed as described in [33]. Pooled $\mathrm{CHCl}_{3}$ phases were evaporated under inert gas $\left(\mathrm{N}_{2}\right)$. The residue was dissolved in $360 \mu \mathrm{L}$ $\mathrm{MeOH}$ and filtrated $(0.22 \mu \mathrm{m})$ prior to loading on RP-HPLC (Dionex HPLC system) with the following parameters and settings: HPLC guard column, VP10/8 Nucleodur C18 Isis (Machery and Nagel, Düren, Germany); HPLC main pillar, VP250/10 Nucleodur C18 Isis, $5 \mu \mathrm{m}$ (Machery and Nagel, Düren, Germany); Solution A (A), 80\% MeOH, 19.9\% Millipore Water (MPW), $0.1 \%$ acetic acid; Solution B (B), $99.9 \% \mathrm{MeOH}, 0.1 \%$ acetic acid, column temperature $30^{\circ} \mathrm{C}$, flow rate $4.166 \mathrm{~mL} /$ minute. After column equilibration for $10 \mathrm{~min}$ with $\mathrm{A}$, the run was started by the injection of $10 \mu \mathrm{L}$ of the synthesis mix. After $9 \mathrm{~min}$, B was increased from $0 \%$ to $25 \%$ within $5 \mathrm{~min}$ and, during the following $2 \mathrm{~min}$, B was increased to $100 \%$. The UV spectrum of the eluate was monitored at $224 \mathrm{~nm}$ (Chromeleon, Version 6.60, Dionex; Thermo Fisher, Waltham, MA, USA).

As for the DHA-LOX product analysis, major peaks fractionating at an elution time of $\sim 13$ min were collected and analyzed with a Q-IMS-TOF mass spectrometer Synapt G2Si (Waters $\mathrm{GmbH}$, Manchester, UK) operated in resolution mode and interfaced to a nano-ESI ion source. $\mathrm{N}_{2}$ served both as the nebulizer gas and the dry gas. $\mathrm{N}_{2}$ was generated with the nitrogen generator NGM 11. Argon served as the collision gas for $\mathrm{MS}^{2}$ experiments by CID (collision-induced dissociation). Samples from the LC-separation were introduced by static nano-ESI using in-house pulled glass emitters. The mass axis was externally calibrated with fragment ions of Glu-1-fibrinopeptide B as the calibration standard. In MS experiments, the protonated signal of leucine-enkephalin was used as an internal mass standard. Scan accumulation and data processing was performed with MassLynx 4.1 (Waters $\mathrm{GmbH}$, Manchester, UK) on a PC workstation. The spectra were generated by accumulating and averaging 50 single spectra. Determinations of the exact masses were performed using centroided data.

ARA-LOX2 product analysis was performed by the comparison of retention times with 15-hydroperoxyarachidonic acid (15-HPETE) standard, prepared by incubation of ARA with SLOX (Sigma-Aldrich, Taufkirchen, Germany, L7395) as described in [32]. 


\subsection{Effect of $\mathrm{pH}$ and Various Compounds on LOX Activities}

The $\mathrm{pH}$ profiles of LOX activities were determined spectrophotometrically with $9.6 \mu \mathrm{M}$ LeA, dissolved in $\mathrm{K}-\mathrm{P}_{\mathrm{i}}, \mathrm{pH}$ 6.6, or Tris-HCl, $\mathrm{pH}$ 7.2-8.6. The effect of chemicals on LOX activity was determined using both techniques: (i) with an $\mathrm{O}_{2}$-electrode by injecting preincubated ( $5 \mathrm{~min}$ at $35^{\circ} \mathrm{C}$ and $5 \mathrm{~min}$ at $25^{\circ} \mathrm{C}$ ) enzyme to $30 \mu \mathrm{M}$ LeA (in $50 \mathrm{mM}$ Tris- $\mathrm{HCl}$, $\mathrm{pH} 7.2)$; and (ii) with a spectrophotometer by incubating $13.5 \mu \mathrm{L}(0.25 \mu \mathrm{g} / \mu \mathrm{L}) 13-\mathrm{LOX}$ with $1.5 \mu \mathrm{L} 2.8 \mathrm{mM}$ chemical stocks or solvent $\left(10 \mathrm{~min}, 30^{\circ} \mathrm{C}\right)$ and the injection of $3 \mu \mathrm{L}$ incubate into $123 \mu \mathrm{L}$ LeA $(4.8 \mu \mathrm{M}$ in $50 \mathrm{mM}$ Tris- $\mathrm{HCl}, \mathrm{pH}$ 7.2). Inhibitory studies were performed spectrophotometrically by the pre-incubation of $15 \mu \mathrm{L}$ enzymes $(0.25 \mu \mathrm{g} / \mu \mathrm{L})$ with $2 \mu \mathrm{L}$ chemical stocks $(120-2880 \mu \mathrm{M})$ or solvent $(0 \mu \mathrm{M})$ for $10 \mathrm{~min}$ at $30^{\circ} \mathrm{C}$, and the successive injection of incubate ( $3 \mu \mathrm{L}$ ) into $123 \mu \mathrm{L} 4.8 \mu \mathrm{M} \mathrm{LeA}$ (in $50 \mathrm{mM}$ Tris- $\mathrm{HCl}$, pH 7.2). This approach was also used for kinetic inhibition studies, using four different substrate concentrations for the determination of inhibition type and inhibitor constant (Ki)-values, with Michaelis-Menten, Lineweaver-Burk and Dixon plots.

The effect of 12-OPDA on LOX4 at two enzyme concentrations in the presence of GSH was analyzed by preincubating $\left(25^{\circ} \mathrm{C}, 5 \mathrm{~min}\right) 1.5 \mu \mathrm{L} 40 \mathrm{mM}$ GSH with $45 \mu \mathrm{L}$ LOX $4(0.27$ or $0.54 \mu \mathrm{g} / \mu \mathrm{L})$ and further incubation $\left(10 \mathrm{~min}, 25^{\circ} \mathrm{C}\right)$ with $5 \mu \mathrm{L}$ 12-OPDA $(1.4 \mathrm{mM}$ in $\mathrm{EtOH}$ ) or EtOH (control). The effect of doubling the GSH concentration was studied as described, using a stock of $80 \mathrm{mM}$ and a LOX4 concentration of $0.54 \mu \mathrm{g} / \mu \mathrm{L}$. The influence of the 12-OPDA-GSH adduct on LOX4 activity was studied by adding $45 \mu \mathrm{L}(0.54 \mu \mathrm{g} / \mu \mathrm{L})$ LOX 4 to $5 \mu \mathrm{L}$ of the 12-OPDA-GSH mixture in $40 \mathrm{mM} \mathrm{K}-\mathrm{P}_{\mathrm{i}}, \mathrm{pH} 8.0$ (see below). The control was performed by adding $5 \mu \mathrm{L}$ GSH mixture excluding 12-OPDA to $45 \mu \mathrm{L}(0.54 \mu \mathrm{g} / \mu \mathrm{L})$, while the 12-OPDA-LOX4 sample was obtained by adding $5 \mu \mathrm{L} 1.4 \mathrm{mM} \mathrm{12-OPDA}$ (in 50\% $\left.40 \mathrm{mM} \mathrm{K}-\mathrm{P}_{\mathrm{i}}, \mathrm{pH} 8.0\right)$ to $45 \mu \mathrm{L}(0.54 \mu \mathrm{g} / \mu \mathrm{L}) \mathrm{LOX} 4$ and incubating at $25^{\circ} \mathrm{C}$ for $10 \mathrm{~min}$. All prepared samples were injected into $20 \mu \mathrm{M}$ LeA, and oxygen consumption was recorded as described. Then, 12-OPDA-GSH adduct was prepared by incubating $\left(35^{\circ} \mathrm{C}, 6 \mathrm{~h}\right) 2.8 \mathrm{mM}$ 12-OPDA (in EtOH) with an equal volume of $35 \mathrm{mM} \mathrm{GSH}$ (in $40 \mathrm{mM} \mathrm{K}-\mathrm{P}_{\mathrm{i}} \mathrm{pH}, 8.0$ ).

\subsection{Effect of Divalent Cations on LOX-Catalyzed LeA Dioxygenation}

The dependence of LOX activity on $\mathrm{CaCl}_{2}, \mathrm{MgCl}_{2}, \mathrm{CdSO}_{4}$ and $\mathrm{CuCl}_{2}$ dissolved in $20 \mathrm{mM}$ HEPES, pH 8.0, was determined $\mathrm{O}_{2}$-polarographically [78]. Briefly, $55.0 \mu \mathrm{L}$ of protein $(0.5 \mu \mathrm{g} / \mu \mathrm{L})$ was injected into an $\mathrm{O}_{2}$-electrode cuvette filled with $30 \mu \mathrm{M}$ LeA $\left( \pm 1.0 \mathrm{mM}\right.$ salts). For $\mathrm{CuCl}_{2}, 100 \mu \mathrm{M}$ was used, due to the strong metal-catalyzed oxidation of LeA. The $\mathrm{Cd}^{2+}$ effect was studied spectrophotometrically, using $4 \mu \mathrm{g}$ LOX2 at indicated concentrations, preincubated for $10 \mathrm{~min}$ at $25^{\circ} \mathrm{C}$. The residual LOX activity was measured by injecting $8 \mu \mathrm{L}$ incubate $(0.2 \mu \mathrm{g} / \mu \mathrm{L})$ into $110 \mu \mathrm{L}$ LeA $(9 \mu \mathrm{M}$ in $20 \mathrm{mM}$ HEPES, pH 8.0). The effect of metals on LOX was studied with E. coli-expressed protein pellets dissolved in TRIS-HCl, $\mathrm{pH}$ 8.0. The protocol followed the details outlined for the determination of the regiospecificity of LOX-mediated DHA and ARA oxygenation (Section 4.5) and used synthesized 12-OPDA and OCPD as described in Section 4.8.

\subsection{LOX-Mediated Synthesis of 12-OPDA, DHA-Peroxide, ARA-Peroxide and OCPD}

Synthesis of 12-OPDA and OCPD with 13-LOX-, AOS- and AOC-lysates was performed as described in [33], here expanded to the testing of LOX2, LOX3 and LOX4. The RP-HPLC analysis of oxylipin extracts was performed as described (see Section 4.5) using an injection volume of $20 \mu \mathrm{L}$. Successful formation of 12-OPDA and OCPD was confirmed by comparing the elution times with standards as synthesized in [33]. The time course of LA, ARA and LeA peroxide formation by LOX2, and consumption by AOS, was demonstrated spectrophotometrically at $234 \mathrm{~nm}$ [77] by adding $3 \mu \mathrm{g}$ LOX2 to $12 \mu \mathrm{M}$ PUFA (in $50 \mathrm{mM}$ Tris- $\mathrm{HCl}, \mathrm{pH} 7.2)$, followed by the addition of $1.5 \mu \mathrm{g}$ AOS in a total volume of $129 \mu \mathrm{L}$. 


\subsection{Determination of Iron Content and Free Cysteines}

The iron content was analyzed as described [79]. Free protein thiols were determined as described in [80] with slight variations. Briefly, $150 \mu \mathrm{L}$ LOX4 $(4.2 \mu \mathrm{M})$ was mixed with $1.5 \mu \mathrm{L} 30 \mathrm{mM}$ 12-OPDA (in EtOH) or EtOH (solvent control). After 20 min of incubation at $25{ }^{\circ} \mathrm{C}$, samples were mixed with $10 \mu \mathrm{L}$ dithionitrobencene (DTNB, $2 \mathrm{mM}$ in $40 \mathrm{mM}$ $\mathrm{K}-\mathrm{P}_{\mathrm{i}}, \mathrm{pH}$ 8.0) and incubated for $30 \mathrm{~min}$ in the dark. Samples were measured at $412 \mathrm{~nm}$, $\varepsilon_{412 \mathrm{~nm}}=13,600 \mathrm{~L}^{-1} \cdot \mathrm{mol}^{-1} \cdot \mathrm{cm}^{-1}\left(\mathrm{KC} 4\right.$ microplate reader, Biotec, $\left.25^{\circ} \mathrm{C}\right)$ for determination of the thiol/protein ratio with background correction $\left(150 \mu \mathrm{L} 40 \mathrm{mM} \mathrm{K}-\mathrm{P}_{\mathrm{i}}, \mathrm{pH} 8.0,10 \mu \mathrm{L}\right.$ DTNB $2 \mathrm{mM}, 1.5 \mu \mathrm{L}$ ligand stock or EtOH).

\subsection{Ex Vivo Evaluation of 12-OPDA as a LOX Inhibitor}

To evaluate 12-OPDA as a LOX inhibitor under native conditions, we employed pea roots as a plant LOX source. The reliability was assessed with the criterion that an increase in $A_{234 n m}$ and, ideally, oxygen consumption occurred via the injection of plant tissue extract $\left(0.5-2 \mu \mathrm{g} / \mu \mathrm{L}\right.$ protein in $50 \mathrm{mM}$ Tris- $\mathrm{HCl}$ or $\mathrm{K}-\mathrm{P}_{\mathrm{i}}, \mathrm{pH}$ 6.6-8.0) in LeA (tested at $4-100 \mu \mathrm{M})$. Furthermore, boiling of plant tissue extract $\left(5 \mathrm{~min}, 95^{\circ} \mathrm{C}\right)$ resulted in decreased activities, determined as described in the following. Pea seeds (Pisum sativum "Kleine Rheinländerin") were placed in darkness for 4 days on moist paper. The emerged roots were cut, frozen in liquid $\mathrm{N}_{2}$, and stored at $-80{ }^{\circ} \mathrm{C}$. Frozen tissue $(\sim 50 \mathrm{mg} / \mathrm{mL})$ was pulverized in a pre-chilled mortar and immediately ground with $50 \mathrm{mM}$ Tris- $\mathrm{HCl}, \mathrm{pH} 7.2$. After centrifugation $\left(14,000 \mathrm{rpm}, 4^{\circ} \mathrm{C}\right)$, the clear supernatant was used as a protein source (pea protein).

The immunological detection of 13-LOX was performed, based on [81]. Pea proteins $(8 \mu \mathrm{g})$ were separated via $7.5 \%$ SDS-PAGE and subsequently transferred (30 min, $2.0 \mathrm{~mA} / \mathrm{cm}^{2}$ ) with Towbin transfer buffer onto nitrocellulose membrane, with semi-dry blotter. After $1 \mathrm{~h}$ blocking with blocking solution $(1 \%(w / v)$ non-fat dry milk in TBST $(150 \mathrm{mM} \mathrm{NaCl}, 50 \mathrm{mM}$ Tris-HCl, $\mathrm{pH} 7.5,0.05 \%$ tween 20$)$ ) and overnight incubation $\left(4^{\circ} \mathrm{C}\right)$ with LOX2 (At3g45140) serum (Agrisera, AS07 258, 1:25,000 in blocking solution), the blot was washed with TBST and incubated $\left(2 \mathrm{~h}, 25^{\circ} \mathrm{C}\right)$ with horseradish peroxidase-coupled anti-rabbit IgG as second antibody (1:20,000 in blocking solution) for the subsequent luminescence detection of immunodecorated LOX on X-ray films (30 s incubation). The effect of 12-OPDA on pea root LOX activity was studied by incubating $60 \mu \mathrm{L}(0.6 \mu \mathrm{g} / \mu \mathrm{L}$ protein $)$ with $2 \mu \mathrm{L} 30 \mathrm{mM}$ 12-OPDA or EtOH (control) for $45 \mathrm{~min}$ at $35^{\circ} \mathrm{C}$. The mixture was injected in $1.8 \mathrm{~mL}$ of $20 \mu \mathrm{M} \mathrm{LeA}$ (in $50 \mathrm{mM}$ Tris- $\mathrm{HCl}, \mathrm{pH} 7.2$ ) and recorded for oxygen consumption.

\section{Conclusions}

This report provides novel insights into the regulatory effects of physiologically relevant compounds on 13-LOX isoforms from $A$. thaliana. We confirmed that all 13-LOXs carry chloroplast signal peptides and are potential sources of 12-OPDA. Our hypothesis of LOX inhibition by 12-OPDA was challenged via two methods, revealing that among recombinantly expressed proteins, LOX3 and LOX4 were the most sensitive to inhibition by 12-OPDA. Thus, feedback modulation of these oxygenases by 12-OPDA might be relevant in vivo, to decrease the potential accumulation of potentially toxic LOX products under conditions of stress. In addition, we found that LOX3 and LOX2 were most sensitive toward inhibition by MJ. Insight into selective interactions is also provided for divalent metals; of which, the highly toxic cadmium metal ion activated LOX2 and inactivated LOX3, LOX4 and LOX6. Furthermore, we suggest similarities between $A$. thaliana 13-LOXs and human LOXs, known to be involved in inflammation and diseases.

Supplementary Materials: Supplementary materials can be found at https:/ /www.mdpi.com/ article/10.3390/ijms221910237/s1.

Author Contributions: Conceptualization, D.M. and K.-J.D.; methodology, D.M., T.S., J.S. and A.V.; investigation, D.M., K.C., S.S., J.S.; data curation, D.M., T.S. and J.S.; writing-original draft 
preparation, D.M.; writing-review and editing, all authors; supervision, K.-J.D.; funding acquisition, K.-J.D. All authors have read and agreed to the published version of the manuscript.

Funding: Support by the DFG (DI 346/17-2 and 22-1) and Bielefeld University is acknowledged.

Institutional Review Board Statement: Not applicable.

Informed Consent Statement: Not applicable.

Data Availability Statement: All necessary data are contained in this paper. Upon request, additional data can be sent.

Acknowledgments: We thank Shanti S. Sharma (Sikkim University, India) for fruitful discussions on cadmium biochemistry.

Conflicts of Interest: The authors encounter no conflict of interest. The funders had no role in the design of the study; in the collection, analyses, or interpretation of data; in the writing of the manuscript, or in the decision to publish the results.

\section{References}

1. Horn, T.; Adel, S.; Schumann, R.; Sur, S.; Kakularam, K.R.; Polamarasetty, A.; Redanna, P.; Kuhn, H.; Heydeck, D. Evolutionary aspects of lipoxygenases and genetic diversity of human leukotriene signaling. Prog. Lipid Res. 2015, 57, 13-39. [CrossRef] [PubMed]

2. Feussner, I.; Wasternack, C. The lipoxygenase pathway. Annu. Rev. Plant Biol. 2002, 53, 275-297. [CrossRef] [PubMed]

3. Funk, C.D. Prostaglandins and leukotrienes: Advances in eicosanoid biology. Science 2001, 294, 1871-1875. [CrossRef]

4. Musiek, E.S.; Brooks, J.D.; Joo, M.; Brunoldi, E.; Porta, A.; Zanoni, G.; Vidary, G.; Blackwell, T.S.; Montine, T.J.; Milne, G.L.; et al. Electrophilic cyclopentenone neuroprostanes are anti-inflammatory mediators formed from the peroxidation of the $\omega-3$ polyunsaturated fatty acid docosahexaenoic acid. J. Biol. Chem. 2008, 283, 19927-19935. [CrossRef]

5. Chen, H.M.; Zhu, Z.J.; Chen, J.J.; Yang, R.; Luo, Q.J.; Xu, J.L.; Shan, H.; Yan, X.J. A multifunctional lipoxygenase from Pyropia haitanensis-The cloned and functioned complex eukaryotic algae oxylipin pathway enzyme. Algal Res. 2015, 12, 316-327. [CrossRef]

6. Djian, B.; Hornung, E.; Ischebeck, T.; Feussner, I. The green microalga Lobosphaera incisa harbours an arachidonate 15Slipoxygenase. Plant Biol. 2019, 21, 131-142. [CrossRef] [PubMed]

7. Mukhtarova, L.S.; Lantsova, N.V.; Khairutdinov, B.I.; Grechkin, A.N. Lipoxygenase pathway in model bryophytes: 12-oxo-9 (13), 15-phytodienoic acid is a predominant oxylipin in Physcomitrella patens. Phytochemistry 2020, 180, 112533. [CrossRef]

8. Monte, I.; Ishida, S.; Zamarreño, A.M.; Hamberg, M.; Franco-Zorrilla, J.M.; García-Casado, G.; Gouhier-Darimont, C.; Reymond, P.; Takahashi, K.; García-Mina, J.M.; et al. Ligand-receptor co-evolution shaped the jasmonate pathway in land plants. Nat. Chem. Biol. 2018, 14, 480-488. [CrossRef]

9. Savadogo, E.H.; Shiomi, Y.; Yasuda, J.; Akino, T.; Yamaguchi, M.; Yoshida, H.; Umegawachi, T.; Tanaka, R.; Suong, D.N.A.; Miura, K.; et al. Gene expression of PLAT and ATS3 proteins increases plant resistance to insects. Planta 2021, 253, 1-16. [CrossRef]

10. Ikei, K.N.; Yeung, J.; Apopa, P.L.; Ceja, J.; Vesci, J.; Holman, T.R.; Holinstat, M. Investigations of human platelet-type 12lipoxygenase: Role of lipoxygenase products in platelet activation. J. Lipid Res. 2012, 53, 2546-2559. [CrossRef]

11. Bonaventure, G.; Salas, J.J.; Pollard, M.R.; Ohlrogge, J.B. Disruption of the FATB gene in Arabidopsis demonstrates an essential role of saturated fatty acids in plant growth. Plant Cell 2003, 15, 1020-1033. [CrossRef] [PubMed]

12. Bannenberg, G.; Martínez, M.; Hamberg, M.; Castresana, C. Diversity of the enzymatic activity in the lipoxygenase gene family of Arabidopsis thaliana. Lipids 2009, 44, 85. [CrossRef]

13. Higashi, Y.; Okazaki, Y.; Takano, K.; Myouga, F.; Shinozaki, K.; Knoch, E.; Fukushima, A.; Saito, K. Heat inducible lipase1 remodels chloroplastic monogalactosyldiacylglycerol by liberating $\alpha$-linolenic acid in Arabidopsis leaves under heat stress. Plant Cell. 2018, 30, 1887-1905. [CrossRef] [PubMed]

14. Kutzner, L.; Goloshchapova, K.; Heydeck, D.; Stehling, S.; Kuhn, H.; Schebb, N.H. Mammalian ALOX15 orthologs exhibit pronounced dual positional specificity with docosahexaenoic acid. Biochim. Biophys. Acta (BBA) Mol. Cell Biol. Lipids 2017, 1862, 666-675. [CrossRef] [PubMed]

15. Wasternack, C.; Hause, B. Jasmonates: Biosynthesis, perception, signal transduction and action in plant stress response, growth and development. An update to the 2007 review in Annals of Botany. Ann. Bot. 2013, 111, 1021-1058. [CrossRef]

16. Stelmach, B.A.; Müller, A.; Hennig, P.; Laudert, D.; Andert, L.; Weiler, E.W. Quantitation of the octadecanoid 12-oxo-phytodienoic acid, a signalling compound in plant mechanotransduction. Phytochemistry 1998, 47, 539-546. [CrossRef]

17. Grebner, W.; Stingl, N.E.; Oenel, A.; Mueller, M.J.; Berger, S. Lipoxygenase 6-dependent oxylipin synthesis in roots is required for abiotic and biotic stress resistance of Arabidopsis. Plant Physiol. 2013, 161, 2159-2170. [CrossRef]

18. Pollmann, S.; Springer, A.; Rustgi, S.; von Wettstein, D.; Kang, C.; Reinbothe, C.; Reinbothe, S. Substrate channeling in oxylipin biosynthesis through a protein complex in the plastid envelope of Arabidopsis thaliana. J. Exp. Bot. 2019, 70, 1483-1495. [CrossRef] [PubMed] 
19. Ziegler, J.; Hamberg, M.; Miersch, O.; Parthier, B. Purification and characterization of allene oxide cyclase from dry corn seeds. Plant Physiol. 1997, 114, 565-573. [CrossRef]

20. Caldelari, D.; Wang, G.; Farmer, E.E.; Dong, X. Arabidopsis lox3 lox4 double mutants are male sterile and defective in global proliferative arrest. Plant Mol. Biol. 2011, 75, 25-33. [CrossRef]

21. Cao, S.; Chen, H.; Zhang, C.; Tang, Y.; Liu, J.; Qi, H. Heterologous expression and biochemical characterization of two lipoxygenases in oriental melon, Cucumis melo var. makuwa Makino. PLoS ONE 2016, 11, e0153801. [CrossRef]

22. Wennman, A.; Oliw, E.H.; Karkehabadi, S.; Chen, Y. Crystal structure of manganese lipoxygenase of the rice blast fungus Magnaporthe oryzae. J. Biol. Chem. 2016, 291, 8130-8139. [CrossRef] [PubMed]

23. Walther, M.; Wiesner, R.; Kuhn, H. Investigations into calcium-dependent membrane association of 15-lipoxygenase-1 mechanistic roles of surface-exposed hydrophobic amino acids and calcium. J. Biol. Chem. 2004, 279, 3717-3725. [CrossRef] [PubMed]

24. Allard, J.B.; Brock, T.G. Structural organization of the regulatory domain of human 5-lipoxygenase. Curr. Protein Pept. Sci. 2005, 6, 125-131. [CrossRef] [PubMed]

25. Eek, P.; Järving, R.; Järving, I.; Gilbert, N.C.; Newcomer, M.E.; Samel, N. Structure of a calcium-dependent 11R-lipoxygenase suggests a mechanism for Ca2+ regulation. J. Biol. Chem. 2012, 287, 22377-22386. [CrossRef]

26. Schaffrath, U.; Zabbai, F.; Dudler, R. Characterization of RCI-1, a chloroplastic rice lipoxygenase whose synthesis is induced by chemical plant resistance activators. Eur. J. Biochem. 2000, 267, 5935-5942. [CrossRef]

27. Feussner, I.; Bachmann, A.; Höhne, M.; Kindl, H. All three acyl moieties of trilinolein are efficiently oxygenated by recombinant His-tagged lipid body lipoxygenase in vitro. FEBS Lett. 1998, 431, 433-436. [CrossRef]

28. Springer, A.; Kang, C.; Rustgi, S.; von Wettstein, D.; Reinbothe, C.; Pollmann, S.; Reinbothe, S. Programmed chloroplast destruction during leaf senescence involves 13-lipoxygenase (13-LOX). Proc. Natl. Acad. Sci. USA 2016, 113, 3383-3388. [CrossRef]

29. Kühn, H.; Barnett, J.; Grunberger, D.; Baecker, P.; Chow, J.; Nguyen, B.; Bursztyn-Pettegrew, H.; Chan, H.; Sigal, E. Overexpression, purification and characterization of human recombinant 15-lipoxygenase. Biochim. Biophys. Acta Mol. Cell Biol. Lipids 1993, 1169, 80-89. [CrossRef]

30. Goloshchapova, K.; Stehling, S.; Heydeck, D.; Blum, M.; Kuhn, H. Functional characterization of a novel arachidonic acid 12S-lipoxygenase in the halotolerant bacterium Myxococcus fulvus exhibiting com-plex social living patterns. MicrobiologyOpen 2019, 8, e00775. [CrossRef]

31. Zhang, L.Y.; Hamberg, M. Specificity of two lipoxygenases from rice: Unusual regiospecificity of a lipoxygenase isoenzyme. Lipids 1996, 31, 803-809. [CrossRef] [PubMed]

32. Ziegler, J.; Wasternack, C.; Hamberg, M. On the specificity of allene oxide cyclase. Lipids 1999, 34, 1005-1015. [CrossRef] [PubMed]

33. Maynard, D.; Müller, S.M.; Hahmeier, M.; Löwe, J.; Feussner, I.; Gröger, H.; Viehhauser, A.; Dietz, K.J. One-pot synthesis of bioactive cyclopentenones from $\alpha$-linolenic acid and docosahexaenoic acid. Bioorg. Med. Chem. 2018, 7, 1356-1364. [CrossRef] [PubMed]

34. Ishijima, S.; Uchibori, A.; Takagi, H.; Maki, R.; Ohnishi, M. Light-induced increase in free $\mathrm{Mg}^{2+}$ concentration in spinach chloroplasts: Measurement of free $\mathrm{Mg}^{2+}$ by using a fluorescent probe and necessity of stromal alkalinization. Arch. Biochem. Biophys. 2003, 412, 126-132. [CrossRef]

35. Tatulian, S.A.; Steczko, J.; Minor, W. Uncovering a calcium-regulated membrane-binding mechanism for soybean lipoxygenase-1. Biochemistry 1998, 37, 15481-15490. [CrossRef]

36. Hammarberg, T.; Provost, P.; Persson, B.; Rådmark, O. The N-terminal domain of 5-lipoxygenase binds calcium and mediates calcium stimulation of enzyme activity. J. Biol. Chem. 2000, 275, 38787-38793. [CrossRef]

37. Mueller, M.J.; Berger, S. Reactive electrophilic oxylipins: Pattern recognition and signalling. Phytochemistry 2009, 70, $1511-1521$. [CrossRef]

38. Kuninori, T.; Nishiyama, J.; Shirakawa, M.; Shimoyama, A. Inhibition of soybean lipoxygenase-1 by n-alcohols and n-alkylthiols. Biochim. Biophys. Acta Mol. Cell Biol. Lipids 1992, 1125, 49-55. [CrossRef]

39. Berger, S.; Weichert, H.; Porzel, A.; Wasternack, C.; Kühn, H.; Feussner, I. Enzymatic and non-enzymatic lipid peroxidation in leaf development. Biochim. Biophys. Acta Mol. Cell Biol. Lipids 2001, 1533, 266-276. [CrossRef]

40. Sanchez-Arcos, C.; Reichelt, M.; Gershenzon, J.; Kunert, G. Modulation of legume defense signaling pathways by native and non-native pea aphid clones. Front. Plant Sci. 2016, 7, 1872. [CrossRef]

41. Cohen, B.S.; Grossman, S.; Pinsky, A. Chlorophyll inhibition of lipoxygenase in growing pea plants. J. Agric. Food Chem. 1984, 32, 516-519. [CrossRef]

42. Maucher, I.V.; Ruehl, M.; Kretschmer, S.B.; Hofmann, B.; Kühn, B.; Fettel, J.; Vogel, A.; Flügel, K.; Manolikakes, G.; Hellmuth, N.; et al. Michael acceptor containing drugs are a novel class of 5-lipoxygenase inhibitor targeting the surface cysteines $\mathrm{C} 416$ and C418. Biochem. Pharmacol. 2017, 125, 55-74. [CrossRef] [PubMed]

43. Gilbert, N.C.; Gerstmeier, J.; Schexnaydre, E.E.; Börner, F.; Garscha, U.; Neau, D.B.; Werz, O.; Newcomer, M.E. Structural and mechanistic insights into 5-lipoxygenase inhibition by natural products. Nat. Chem. Biol. 2020, 16, 783-790. [CrossRef] [PubMed]

44. Schäfer, M.; Fan, Y.; Gu, T.; Heydeck, D.; Stehling, S.; Ivanov, I.; Yao, Y.G.; Kuhn, H. The lipoxygenase pathway of Tupaia belangeri representing Scandentia. Genomic multiplicity and functional characterization of the ALOX15 orthologs in the tree shrew. Biochim. Biophys. Acta Mol. Cell Biol. Lipids 2020, 1865, 158550. [CrossRef] [PubMed]

45. König, S.; Romp, E.; Krauth, V.; Rühl, M.; Dörfer, M.; Liening, S.; Hoffman, B.; Häfner, A.K.; Steinhilber, D.; Karas, M.; et al. Melleolides from honey mushroom inhibit 5-lipoxygenase via CYS159. Cell Chem. Biol. 2019, 26, 60-70. [CrossRef] 
46. Marvian-Hosseini, Z.; Asoodeh, A. Biochemical characterization of purified lipoxygenase from sesame (Sesamum indicum). Int. J. Food Prop. 2017, 20, S948-S958. [CrossRef]

47. Macri, F.; Braidot, E.; Petrussa, E.; Vianello, A. Lipoxygenase activity associated to isolated soy-bean plasma membranes. Biochim. Biophys. Acta Mol. Cell Biol. Lipids 1994, 1215, 109-114. [CrossRef]

48. Yamamoto, S. Mammalian lipoxygenases: Molecular structures and functions. Biochim. Biophys. Acta Mol. Cell Biol. Lipids 1992, 1128, 117-131. [CrossRef]

49. Peltier, J.B.; Ytterberg, A.J.; Sun, Q.; van Wijk, K.J. New functions of the thylakoid membrane proteome of Arabidopsis thaliana revealed by a simple, fast, and versatile fractionation strategy. J. Biol. Chem. 2004, 279, 49367-49383. [CrossRef]

50. Iglesias, J.; Trigueros, M.; Rojas-Triana, M.; Fernández, M.; Albar, J.P.; Bustos, R.; Paz-Ares, J.; Rubio, V. Proteomics identifies ubiquitin-proteasome targets and new roles for chromatin-remodeling in the Arabidopsis response to phosphate starvation. J. Proteom. 2013, 94, 1-22. [CrossRef]

51. Royo, J.; Vancanneyt, G.; Pérez, A.G.; Sanz, C.; Störmann, K.; Rosahl, S.; Sánchez-Serrano, J.J. Characterization of three potato lipoxygenases with distinct enzymatic activities and different organ-specific and wound-regulated expression patterns. J. Biol. Chem. 1996, 271, 21012-21019. [CrossRef]

52. Chauvin, A.; Caldelari, D.; Wolfender, J.L.; Farmer, E.E. Four 13-lipoxygenases contribute to rapid jasmonate synthesis in wounded Arabidopsis thaliana leaves: A role for lipoxygenase 6 in responses to long-distance wound signals. New Phytol. 2013, 197, 566-575. [CrossRef]

53. Friedman, R. Structural and computational insights into the versatility of cadmium binding to proteins. Dalton Trans. 2014, 43 , 2878-2887. [CrossRef]

54. Ritter, A.; Goulitquer, S.; Salaün, J.P.; Tonon, T.; Correa, J.A.; Potin, P. Copper stress induces biosynthesis of octadecanoid and eicosanoid oxygenated derivatives in the brown algal kelp Laminaria digitata. New Phytol. 2008, 180, 809-821. [CrossRef]

55. Yan, J.; Chia, J.C.; Sheng, H.; Jung, H.I.; Zavodna, T.O.; Zhang, L.; Huang, R.; Jiao, C.; Craft, E.J.; Fei, Z.; et al. Arabidopsis pollen fertility requires the transcription factors CITF1 and SPL7 that regulate copper delivery to anthers and jasmonic acid synthesis. Plant Cell. 2017, 29, 3012-3029. [CrossRef]

56. Lei, G.J.; Sun, L.; Sun, Y.; Zhu, X.F.; Li, G.X.; Zheng, S.J. Jasmonic acid alleviates cadmium toxicity in Arabidopsis via suppression of cadmium uptake and translocation. J. Integr. Plant Biol. 2020, 62, 218-227. [CrossRef]

57. Montillet, J.L.; Cacas, J.L.; Garnier, L.; Montané, M.H.; Douki, T.; Bessoule, J.J.; Kowalczyck, L.P.; Maciejewska, U.; Agnel, J.P.; Vial, A.; et al. The upstream oxylipin profile of Arabidopsis thaliana: A tool to scan for oxidative stresses. Plant J. 2004, 40, 439-451. [CrossRef]

58. Wu, H. Affecting the activity of soybean lipoxygenase-1. J. Mol. Graph. Model 1996, 14, 331-337. [CrossRef]

59. Conrad, D.J. The arachidonate 12/15 lipoxygenases. Clin. Rev. Allergy Immunol. 1999, 17, 71-89. [CrossRef]

60. Chauvin, A.; Lenglet, A.; Wolfender, J.L.; Farmer, E. Paired hierarchical organization of 13-lipoxygenases in Arabidopsis. Plants 2016, 5, 16. [CrossRef]

61. Egan, R.W.; Gale, P.H. Inhibition of mammalian 5-lipoxygenase by aromatic disulfides. J. Biol. Chem. 1985, 260, 11554-11559. [CrossRef]

62. Flatman, S.; Hurst, J.S.; McDonald-Gibson, R.G.; Jonas, G.E.; Slater, T.F. Biochemical studies on a 12-lipoxygenase in human uterine cervix. Biochim. Biophys. Acta Gen. Subj. 1986, 883, 7-14. [CrossRef]

63. Hardy, D.J.; Gallegos, M.V.; Gaunt, J.K. Extracts of Pisum sativum metabolise phospholipid via a lipoxygenase-like mechanism. Phytochemistry 1991, 30, 2889-2894. [CrossRef]

64. Bell, E.; Mullet, J.E. Characterization of an Arabidopsis lipoxygenase gene responsive to methyl jasmonate and wounding. Plant Physiol. 1993, 103, 1133-1137. [CrossRef] [PubMed]

65. Pauwels, L.; Morreel, K.; De Witte, E.; Lammertyn, F.; Van Montagu, M.; Boerjan, W.; Inzé, D.; Goossens, A. Mapping methyl jasmonate-mediated transcriptional reprogramming of metabolism and cell cycle progression in cultured Arabidopsis cells. Proc. Natl. Acad. Sci. USA 2008, 105, 1380-1385. [CrossRef] [PubMed]

66. Mphahlele, M.J.; Gildenhuys, S.; Agbo, E.N. In vitro evaluation and docking studies of 5-oxo-5H-furo [3, 2-g] chromene-6carbaldehyde derivatives as potential anti-Alzheimer's agents. Int. J. Mol. Sci. 2019, 20, 5451. [CrossRef]

67. Mogul, R.; Johansen, E.; Holman, T.R. Oleyl sulfate reveals allosteric inhibition of soybean lipoxygenase-1 and human 15lipoxygenase. Biochemistry 2000, 39, 4801-4807. [CrossRef]

68. Löwe, J.; Dietz, K.J.; Gröger, H. From a biosynthetic pathway toward a biocatalytic process and chemocatalytic modifications: Three-step enzymatic cascade to the plant metabolite cis-(+)-12-OPDA and metathesis-derived products. Adv. Sci. 2020, 7, 1902973. [CrossRef]

69. Waterhouse, A.; Bertoni, M.; Bienert, S.; Studer, G.; Tauriello, G.; Gumienny, R.; Heer, F.T.; de Beer, T.A.P.; Rempfer, C.; Bordoli, L.; et al. SWISS-MODEL: Homology modelling of protein structures and complexes. Nucleic Acids Res. 2018, 46, W296-W303. [CrossRef]

70. Pettersen, E.F.; Goddard, T.D.; Huang, C.C.; Couch, G.S.; Greenblatt, D.M.; Meng, E.C.; Ferrin, T.E. UCSF Chimera-A visualization system for exploratory research and analysis. J. Comput. Chem. 2004, 25, 1605-1612. [CrossRef]

71. Grosdidier, A.; Zoete, V.; Michielin, O. SwissDock, a protein-small molecule docking web service based on EADock DSS. Nucleic Acids Res. 2011, 39, W270-W277. [CrossRef] 
72. Liu, Y.; Grimm, M.; Dai, W.-T.; Hou, M.-C.; Xiao, Z.-X.; Cao, Y. CB-Dock: A web server for cavity detection-guided protein-ligand blind docking. Acta Pharmacol. Sin. 2019, 41, 138-144. [CrossRef] [PubMed]

73. O'Boyle, N.M.; Banck, M.; James, C.A.; Morley, C.; Vandermeersch, T.; Hutchison, G.R. Open Babel: An open chemical toolbox. J. Cheminform. 2011, 3, 1-14. [CrossRef] [PubMed]

74. Sievers, F.; Wilm, A.; Dineen, D.; Gibson, T.J.; Karplus, K.; Li, W.; López, R.; McWilliam, H.; Remmert, M.; Söding, J.; et al. Fast, scalable generation of high-quality protein multiple sequence alignments using Clustal Omega. Mol. Syst. Biol. 2011, 7, 539. [CrossRef]

75. Lu, W.; Zhao, X.; Xu, Z.; Dong, N.; Zou, S.; Shen, X.; Huang, J. Development of a new colorimetric assay for lipoxygenase activity. Anal. Biochem. 2013, 441, 162-168. [CrossRef] [PubMed]

76. Seidel, T.; Kluge, C.; Hanitzsch, M.; Roß, J.; Sauer, M.; Dietz, K.J.; Golldack, D. Colocalization and FRET-analysis of subunits c and a of the vacuolar H+-ATPase in living plant cells. J. Biotechnol. 2004, 112, 165-175. [CrossRef]

77. Vick, B.A. A spectrophotometric assay for hydroperoxide lyase. Lipids 1991, 26, 315-320. [CrossRef]

78. Ferreira, C.M.; Pinto, I.S.; Soares, E.V.; Soares, H.M. (Un) suitability of the use of pH buffers in biological, biochemical and environmental studies and their interaction with metal ions-A review. RSC Adv. 2015, 5, 30989-31003. [CrossRef]

79. Fish, W.W. Rapid colorimetric micromethod for the quantitation of complexed iron in biological samples. Methods Enzymol. 1988, 158, 357-364. [CrossRef]

80. Zaffagnini, M.; Michelet, L.; Massot, V.; Trost, P.; Lemaire, S.D. Biochemical characterization of glutaredoxins from Chlamydomonas reinhardtii reveals the unique properties of a chloroplastic CGFS-type glutaredoxin. J. Biol. Chem. 2008, 283, 8868-8876. [CrossRef]

81. Towbin, H.; Staehelin, T.; Gordon, J. Electrophoretic transfer of proteins from polyacrylamide gels to nitrocellulose sheets: Procedure and some applications. Proc. Natl. Acad. Sci. USA 1979, 76, 4350-4354. [CrossRef] 